NBER WORKING PAPER SERIES

\title{
GANG RULE: UNDERSTANDING AND COUNTERING CRIMINAL GOVERNANCE
}

\author{
Christopher Blattman \\ Gustavo Duncan \\ Benjamin Lessing \\ Santiago Tobón \\ Working Paper 28458 \\ http://www.nber.org/papers/w28458 \\ NATIONAL BUREAU OF ECONOMIC RESEARCH \\ 1050 Massachusetts Avenue \\ Cambridge, MA 02138
}

February 2021, Revised April 2023

For comments and feedback we thank Ana Arjona, Oriana Bandiera, Abhijit Banerjee, Eli Berman, Esther Duflo, Leopoldo Fergusson, Claudio Ferraz, Danilo Friere, Soeren Henn, Macartan Humphreys, Stephen Machin, Martin McGuire, Ted Miguel, Mushfiq Mobarak, Eduardo Montero, Daniel Ortega, Gerard Padró i Miquel, Paolo Pinotti, Bob Powell, Gérard Roland, Pieter Serneels, Jake Shapiro, Stergios Skaperdas, Tara Lyn Slough, Carlos SchmidtPadilla, Rodrigo Soares, Maria Micaela Sviatschi, Lucia Tiscornia, Francesco Trebbi, Juan Vargas, Maarten Voors, Jeremy Weinstein, Austin Wright, participants at several seminars and conferences, and Raul Sánchez de la Sierra who was instrumental in conceptualizing the model. Innovations for Poverty Action coordinated all research activities. For research assistance we thank Bruno Aravena Maguida, David Cerero, Peter Deffebach, Sebastián Hernández, Sofía Jaramillo, Juan F. Martínez, Juan Pablo Mesa-Mejía, Angie Mondragón, Helena Montoya, José Miguel Pascual, Andrés Preciado, María-Aránzazu Rodríguez-Uribe, Zachary Tausanovitch, Nelson Matta- Colorado and Martín Vanegas. We thank the Secretariat of Security of Medellín for their cooperation, especially the former Secretary of Security Andrés Tobón, as well as Lina Calle, Ana María Corpas and Andrés Machuca. For financial support, we thank the Centro de Estudios sobre Seguridad y Drogas (CESED) of Universidad de los Andes; the Peace and Recovery Program (P\&R) at Innovations for Poverty Action (IPA); the PROANTIOQUIA foundation; The National Science Foundation (NSF); the UK Foreign, Commonwealth \& Development Office trough the Crime and Violence Initiative at J-PAL; and the Economic Development and Institutions Programme (EDI) funded with UK aid from the UK Government, working in partnership with Oxford Policy Management Limited, University of Namur, Paris School of Economics and Aide á la Décision Économique. The views expressed herein are those of the authors and do not necessarily reflect the views of the National Bureau of Economic Research.

NBER working papers are circulated for discussion and comment purposes. They have not been peer-reviewed or been subject to the review by the NBER Board of Directors that accompanies official NBER publications.

(C) 2021 by Christopher Blattman, Gustavo Duncan, Benjamin Lessing, and Santiago Tobón. All rights reserved. Short sections of text, not to exceed two paragraphs, may be quoted without explicit permission provided that full credit, including $(\mathbb{C}$ notice, is given to the source. 
Gang rule: Understanding and Countering Criminal Governance

Christopher Blattman, Gustavo Duncan, Benjamin Lessing, and Santiago Tobón

NBER Working Paper No. 28458

February 2021, Revised April 2023

JEL No. C93,E26,H11,K42,O17

\begin{tabular}{|c|c|}
\hline \multicolumn{2}{|c|}{$\underline{\text { ABSTRACT }}$} \\
\hline \multicolumn{2}{|c|}{$\begin{array}{l}\text { Criminal groups govern millions worldwide. Even in strong states, gangs resol } \\
\text { provide security. Why do these duopolies of coercion emerge? In many cases, ga } \\
\text { of official order. If so, increasing state presence should crowd out criminal gov } \\
\text { paper, however, we show that state and gang rule are sometimes complement } \\
\text { gangs can deter state predation by keeping neighborhoods orderly and loyal. If } \\
\text { state presence could increase gang rule. We investigate in Medellín, Colombia. } \\
\text { told us they rule mainly to protect drug rents. We test gang responses to state } \\
\text { geographic discontinuity. Internal border changes in } 1987 \text { assigned some } \\
\text { exogenously closer to state security for three decades. Gangs responded to close } \\
\text { by increasing governance services, but primarily in neighborhoods with the g } \\
\text { drug rents. This suggests new strategies for countering criminal governance. }\end{array}$} \\
\hline $\begin{array}{l}\text { Christopher Blattman } \\
\text { Harris School of Public Policy } \\
\text { The University of Chicago } \\
1307 \text { E 60th St } \\
\text { Chicago, IL } 60637 \\
\text { and NBER }\end{array}$ & $\begin{array}{l}\text { Benjamin Lessing } \\
\text { Department of Political Scie } \\
\text { University of Chicago } \\
5828 \text { S. University Ave } \\
\text { Chicago, IL } 60637 \\
\text { blessing@uchicago.edu }\end{array}$ \\
\hline $\begin{array}{l}\text { Gustavo Duncan } \\
\text { Department of Political Science } \\
\text { Universidad EAFIT } \\
\text { Carrera } 49 \text { N } 7 \text { Sur } 50 \\
\text { Medellin, Colombia }\end{array}$ & $\begin{array}{l}\text { Department of Economics } \\
\text { Universidad EAFIT } \\
\text { Carrera } 49 \text { N } 7 \text { Sur } 50 \\
\text { Medellin, Colombia } \\
\text { stobonz@ eafit.edu.co }\end{array}$ \\
\hline
\end{tabular}

gduncan@eafit.edu.co 


\section{Introduction}

For tens of millions of people worldwide, basic social order, property-rights, and dispute resolution are provided by criminal organizations in addition to the state. Such criminal governance is common in Latin American cities, but gangs also rule civilians in Italy, the United Kingdom, India, South Africa, and the American prison system (Arias, 2006; Lessing et al., 2019; Lessing, 2020; Melnikov et al., 2021).

Warlords, crime bosses and other specialists in violence have always emerged to provide security and adjudication in return for taxes and rents (Tilly, 1985; North et al., 2009; Sánchez De La Sierra, 2020). What is interesting about criminal governance today is that it has survived the growth of strong states. In many countries, the government does not have a monopoly on the legitimate use of force in large swathes of their territory. The state typically dominates wealthy areas, but residents of low- and middle-income neighborhoods often live under a duopoly of coercion (Skaperdas and Syropoulos, 1996).

In cities with powerful gangs and gang rule, mayors and police chiefs have few more important concerns. Most cities, however, have no data on the extent of gang rule, its popularity, or the consequences for state service delivery and legitimacy in the short and long run. Moreover, governments don't know how to respond, or what gangs and communities will do in return.

This paper investigates how this duopoly functions in a particular case: Medellín, Colombia. We first describe how this clandestine system works. We then explore how gangs respond to state presence, and under what circumstances a state can crowd gangs and establish a monopoly of rule.

The most common view is that criminal and state rule are substitutes, and that organized crime fills a vacuum left by weak states (Gambetta, 1996; Skaperdas, 2001; Skarbek, 2011). The policy implication is that states can crowd out gang rule by improving the quality and reach of their services, eventually reaching a monopoly on protection and coercion.

While this is often true, in this paper we show that there are times when state and gang rule are strategic complements. In Medellín, some gangs keep order in order to reduce civilian demand for and collaboration with police. They do so primarily when they have illicit rents to protect. This implies that efforts to crowd out gangs could backfire, and changes how cities should approach the issue of gang rule.

As Colombia's second-largest city and commercial heart, Medellín is prosperous, collects extensive tax revenues, and provides considerable public goods and social services to its citizens. Nonetheless, virtually every low- and middle-income neighborhood in the city is also occupied by one of more than 350 small gangs called combos, and most combos engage 
in at least some governance activities. These include prohibiting and punishing property crime, settling disputes between neighbors, enforcing rules, and (in exchange) taxing locals.

We began our study with qualitative interviews with criminal organizations. Whereas previous economist-ethnographer collaborations - such as Levitt and Venkatesh (2000) or Sánchez De la Sierra et al. (2022) — gained deep access to a single illegal group, we develop sources in 41 groups at a more moderate depth, interviewing dozens of leaders and middle managers over 6 years.

We then collected systematic data on criminal governance. In 2019 we ran a representative, city-wide survey of roughly 7,000 residents and businesses, focusing on who provides governance services in their neighborhood, who collects taxes and extortion, and who they see as legitimate and why. Gang governance is routine enough that residents appear to report it faithfully — something we confirm using survey experiments.

The survey data reveal that, while the state is the predominant provider of protection, the combo is seldom far behind. Indeed, in a third of the blocks, residents reported that the combo is the leading provider of security and dispute resolution. Typically, combos collect security fees for these services. But while taxing residents involves a degree of coercion, many payees say they value the services, and that they see the combos as legitimate.

Several criminal leaders told us, however, that they govern not for the direct profits, but rather because it protects their other business lines, especially drug sales. Providing neighborhood order reduces the need for routine police patrols and special agents to enter. When police do enter, residents who feel loyalty to the gangs are less likely to inform on gang members, and may even actively help them hide.

We capture these countervailing criminal responses in a model of imperfect competition that allows for externalities from rule. Standard duopolistic competition implies that gang and state rule are strategic substitutes. In that case, a gang's best response to greater state rule is to reduce the quantity of governance offered. But if we introduce positive externalities to citizen loyalty in other business lines (such as the drug market) this can generate strategic complementarities between gang and state rule. In that case, gangs may increase rule in response to state presence. Finally, we show that these complementarities will be greater if state rule fosters local economic development. This increases the number of transactions and raising residents' demand for governance of all kinds-including gang rule.

To test these qualitative accounts and model, we study an accidental but decades-long reallocation in the local presence of state services in Medellín. We take advantage of a natural experiment: a city bill that, in the late 1980s, reorganized Medellín into 16 areas called comunas. The bill also mandated that all security and protective services-policing, dispute resolution, and family services - be organized by comuna. Therefore, street blocks on 
either side of the new internal borders were similar in demographic and economic terms, but from the 1990s onwards, one received a "distance shock" and was assigned to state protection further away. Access to almost all other government services - schools, healthcare, and social assistance - were unaffected by the reform.

Figure 1 illustrates the intuition behind our empirical strategy. Initially, a pair of nearby blocks $i$ and $j$ received their security and dispute resolution services from the same state headquarters, as seen on the left. These blocks were roughly 1,000 meters from their nearest headquarters on average. Once the new border was introduced, as seen on the right, block $i$ was assigned to be supported by a more distant headquarters - about 400 meters further away on average. Thus, the new borders introduced idiosyncratic increases in distance to police and dispute resolution in one of each pair - a "distance shock." Three decades later, we can assess how combo governance evolved in response to this distance shock.

This strategy uses a geographic boundary as a regression discontinuity. It is identified under a number of the same assumptions as a standard regression discontinuity with two running variables (Keele and Titiunik, 2015). A recent example is that of Henn (2022), who examined how international borders in Africa affect the proximity of the capital to traditional chiefdoms. There are some unusual aspects of our setting, however. One is that Medellín's new borders do not assign treatment in a uniform direction. A block pair located on the far right of Figure 1 would receive the reverse of the illustrated shock. Another feature is that the treatment is not discrete - the new borders assign a continuous exogenous distance shock to each border-pair. Both features are advantageous, however, as they increase the amount of identifying variation.

A key identifying assumption is that no other characteristic changed discontinuously along the new borders unless it was a consequence of this proximity to state protection services. Consistent with this, we see that the block pairs are balanced according to a wide range of initial characteristics that could confound our estimates, including demographics as well as distance to other social services, infrastructure, and business agglomerations. To account for any unobserved confounders, we conduct placebo tests of alternate borders and see no evidence of discontinuities there.

We use our 2019 survey to assess the long run effects of the distance shock on levels of governance and legitimacy of both the state and combo. Not surprisingly, growing closer to the police and municipal headquarters increases reports of state governance. For instance, on blocks assigned to be 400 meters closer to their police and municipal dispute resolution agencies (the median change), residents reported $12 \%$ higher state responsiveness to disputes and disorder. This suggests that proximity matters for projecting state power.

On average, the combos responded by governing more. Growing 400 meters closer to 
Figure 1: Stylized illustration of the natural experiment
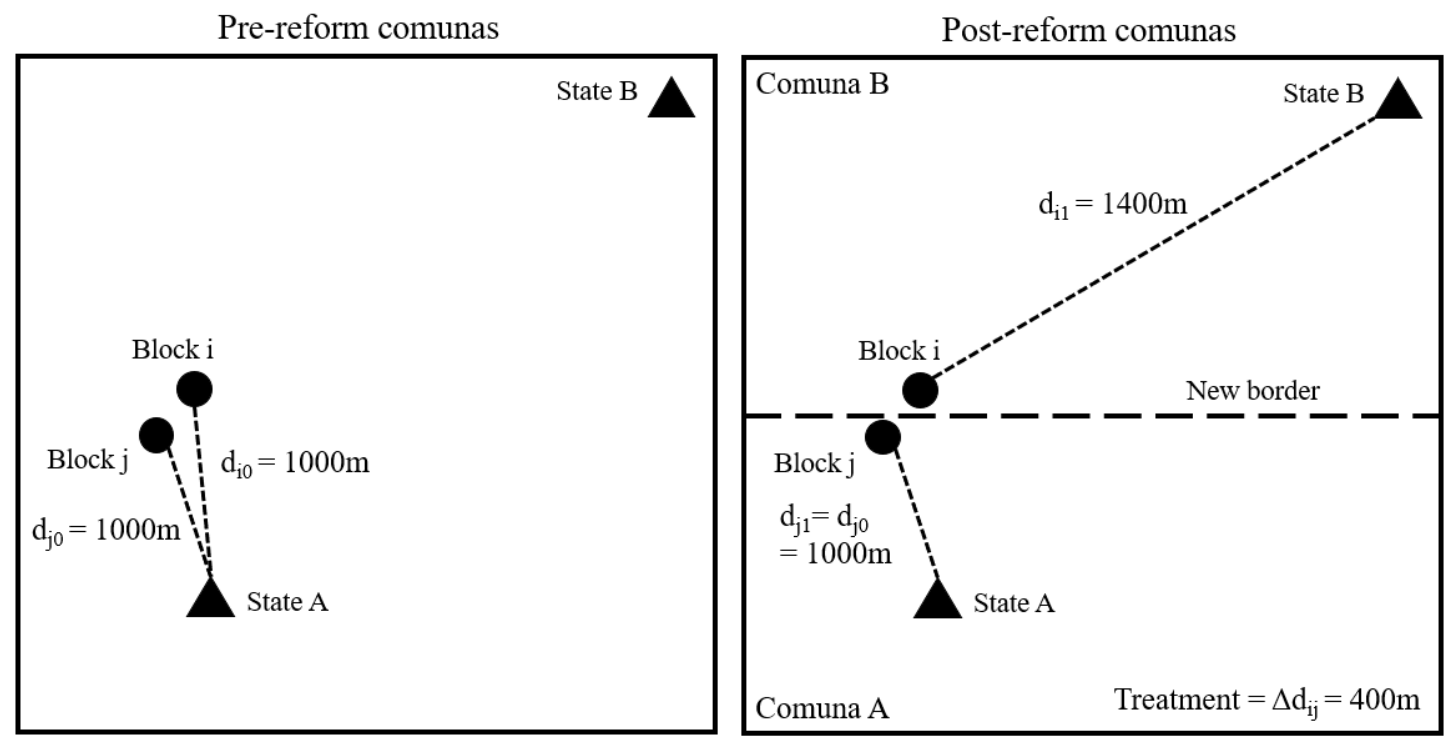

Notes: On the left is a stylized representation of a single pre-1987 comuna, with blocks $i$ and $j$ accessing the state at its closest location (State $A$ ). On the right is a representation of the split comuna after 1987, with block $i$ being assigned to access the state at a further location (State $B$ ) and block $j$ still accessing the state nearby (State $A$ ). See section 5 for details.

state headquarters increases reports of combo rule by $25 \%$. This implies the combo is about twice as responsiveness as the state. One reason is that the state takes several measures to distribute services as evenly as possible across the comuna, and this moderates the relationship with distance. In addition, combos are allocating where they govern and tax within a relatively small territory, and they may be especially sensitive to state proximity.

This combo governance response is greatest in the neighborhoods close to profitable drug markets. One of the challenges with testing this hypothesis is that Medellín's retail drug market emerged post-treatment, in the 2000s and exploded in the 2010s. To develop a pretreatment measure of potential profitability, we use machine learning to predict proximity to future drug markets. We leverage baseline data on local demographics and development, as well as distances to wealthy neighborhoods and business agglomerations. These measures predict drug market locations and seizures decades later-especially proximity to wealthier neighborhoods. On the blocks with the lowest potential drug rents, combos do not respond to state presence by governing more. On blocks with the highest future potential profits, however, the combo response is dramatic.

Meanwhile, we see little evidence that state presence prompted economic development and in-migration, raising the general demand for governance. We cannot rule out modest growth effects from state and combo rule, but the evidence suggests that the primary mechanism connecting state and combo governance is the protection of rents. 
Altogether, these results suggest that gang rule might be more of a problem for "semistrong states" than for weak ones. By this we mean governments that are powerful enough to create illicit markets and challenge criminal gangs, yet too weak to eliminate them entirely. This could help explain why gangs and gang rule are a problem in low- and middle-income neighborhoods rather than high-income ones, where stronger state presence and private security have crowded gangs out. ${ }^{1}$

Gang rule may also be a phenomenon that emerges alongside a retail drug trade (or other illicit rents). For example, in eastern Congo, Sánchez De La Sierra (2020) shows how roving warlords turn themselves into stationary bandits and deliver security when mining rents grow large and can be taxed.

In contrast, a study of gangs in El Salvador found that they are extortionate and repressive, and do little to provide order and dispute resolution or earn civilian loyalty (Melnikov et al., 2021). One reason could be the absence of a retail drug trade in El Salvador. Without this incentive to foster order, the gangs can afford to be repressive and illegitimate.

There are also parallels to a counter-insurgency literature arguing that rebel groups offer justice and welfare services to capture civilian "hearts and minds." ${ }^{2}$ Some argue that military action plus state services can raise state legitimacy and crowd out insurgents (Berman and Matanock, 2015). This raises the question: Why would village insurgents be crowded out when city gangs are not? One possible answer is that rural insurgents have wide areas of operation, where no one town or village is strategic, while urban gangs have small, welldefined territories and are hemmed in by rivals. Gangs have nowhere else to go.

We can see this rural-urban difference among criminal groups as well. Studying the attempted pacification of Rio's favelas, Magaloni et al. (2020) show that gangs resist state incursions more violently in the neighborhoods they rule. In Mexico, however, the drug trafficking organizations have a more diffuse base of operations. Many routes can carry their product to the United States. Thus, crackdowns in one city simply displace traffickers and violence to less aggressive municipalities nearby (Dell, 2015).

Policy-wise, our results suggest governments will need to go beyond piecemeal statebuilding to counter gang rule, perhaps by trying to shape local norms of combo legitimacy, or undermining drug profits. But caution is warranted. Our interviews, model, and empirical results suggest that gang violence is disciplined by the existence of criminal rents and the

\footnotetext{
${ }^{1}$ There are also parallels to a literature on governance by traditional leaders and civil society organizations, which shows that these organizations can be substitutes or complements depending on the circumstances (e.g. Acemoglu et al., 2020; Cammett and MacLean, 2014; Henn, 2022).

${ }^{2}$ See, for instance, Berman et al. (2011, 2013); Crost et al. (2016). This is part of a more widely-studied phenomenon of rebel governance, when insurgencies try to foster civilian support not only in a contest for rents but also for control of the state itself (Arjona, 2016).
} 
need for local order. Undermining drug profits could result in more ruthless, extractive, and violent organizations - a difficult policy trade-off.

Other evidence from Medellín suggests that state building on the margin is an enduring challenge. Blattman, Duncan, Lessing, and Tobon (2023) examine a 2-year experiment that increased non-police state presence in dozens of small neighborhoods. They find that it is hard to shift citizen impressions of state responsiveness, quality, and legitimacy even with a large increase in street-level bureaucrats. This implies that state-building efforts, and attempts to discipline gangs, may need to be long and sustained (like the one in this paper). ${ }^{3}$

\section{Data and methods}

\subsection{Qualitative interviews}

To understand these clandestine organizations and systems of rule, we began with interviews of gang members and leaders. Over six years we interviewed 118 criminal leaders and members across 41 groups in Medellín. These 41 include 28 combos as well as 13 higher-level, mafia-like organizations called razones, discussed below. Our highest-ranking sources are deputies to the most powerful crime bosses in the city. Most are lower in the hierarchy. ${ }^{4}$

This is a convenience sample of criminal actors who were willing to speak. We conducted roughly half the interviews in prisons, typically in a wing reserved for high- and middle-ranking criminals. Most continue to run their group's activities while imprisoned. ${ }^{5}$ Eventually, we developed criminal contacts and referrals outside of prison.

In addition to these criminal group interviews, we interviewed local crime experts, members of the Metropolitan Police and the Attorney General's office, and also obtained confidential internal law-enforcement reports. Our research assistants also conducted 153 interviews

\footnotetext{
${ }^{3}$ We separate this paper for two reasons. First, the treatments are distinct - a short run change in mayoral staff as opposed to a decades-long change in policing and city services. Second, the concepts are distinct. The experiment studies the effect of increasing state presence on citizen perceptions of state services and legitimacy, not combo governance. As the state's efforts backfired in that particular intervention, it has become a study of heterogeneity in state failure rather than a study of gang rule.

${ }^{4}$ Most information on criminal markets and organizations comes from secondary sources, such as judicial proceedings or police investigations. Some prominent examples include case studies of the Sicilian mafia (Gambetta, 1996), New York mafia (Reuter, 1983), pirates (Leeson, 2007), and Brazilian and American prison gangs (Skarbek, 2014; Lessing and Denyer Willis, 2019). Some examples of primary sources include Levitt and Venkatesh (2000) on a defunct Chicago gang and Sánchez De la Sierra et al. (2022) on corrupt Congolese traffic police.

${ }^{5}$ In the beginning, prison wardens announced that anyone who would like to meet with university professors could meet us at a particular room and time. Following this, our sources might or might not continue to make appointments. Some referred us to additional sources. Because the prison affords little privacy, most interviews took place in public areas, out of earshot from most inmates or prison guards, but in public view, usually for one hour.
} 
Table 1: Interviews by respondent type

\begin{tabular}{clc}
\hline & Respondent type & $\begin{array}{c}\text { Total \# of } \\
\text { participants }\end{array}$ \\
\hline & Incarcerated subjects: & 32 \\
& Active or former combo & 21 \\
& Active or former razón & 3 \\
Criminal actors & Other illegal organization & \\
& Subjects outside prison: & 38 \\
& Active combo member & 37 \\
& Former combo member & 11 \\
& Active razón member & 1 \\
& Active faction member & 4 \\
\hline \multirow{2}{*}{ Community } & Other illegal organization & 131 \\
& Member & 23 \\
& Leader & 10 \\
\hline \multirow{2}{*}{ Experts } & Shopkeeper & 16 \\
& Criminal group experts & 2 \\
\hline \multirow{2}{*}{ Public } & Other & 17 \\
servants & City officials (active or former) & 19 \\
& Police (active or former) & 10 \\
\hline Total & Prosecutor (active or former) & 381 \\
\hline
\end{tabular}

with community leaders and members in around 108 neighborhoods, mainly on the subject of citizen interactions with organized criminals and use of their services and governing activities.

Data quality We believe our subjects spoke to us for several reasons. In prison, our interviews offered subjects a respite from routine and a chance to exhibit their expertise and insights. Interviews also posed little risk, since most subjects had already been prosecuted for the criminal activities they described. They were generally flattered by academic attention, and many harbored hopes of being the subject of books. Finally, some leaders remarked that the government underestimated their strength, that this interfered with bargaining, and that we could resolve this as we seemed to have a more accurate understanding of the situation.

We believe our informants were truthful for several reasons. First, for the most part, gang organization and rule is a non-sensitive subject and is not a prosecutable offense. Second, we sought to validate our observations with multiple sources. For most topics we discuss we have at least 2-3 sources between gang members, ex-members, and experts. Nonetheless, for obvious reasons we cannot trust these qualitative data entirely. 
Qualitative methods To ensure these qualitative data were systematically collected and analyzed, and to collect a large volume of qualitative information (and to conduct validation exercises), we formed a collaboration between two economists and two ethnographers. We developed semi-structured interview guides, and adjusted them to investigate hypotheses as we developed them. We recorded and transcribed interviews when possible. When not possible, especially in prison, we took notes and wrote them up formally after each interview.

To improve access, we also hired the city's main organized-crime journalist as a consultant, to provide introductions as well as conduct his own interviews and analysis. We also hired a government gang outreach worker (himself a former street-gang member and prisongang leader), who became a full-time research associate. He conducted structured interviews with criminal subjects in his personal network.

To organize the vast number of interviews, we created a private encrypted wiki we call WikiCombo. A collaborative wiki was a good fit for the networked, non-linear nature of the data, especially when collected by several contributors. We uploaded and encrypted all primary and secondary sources. Factual claims are linked directly to original transcripts.

Ethics and human subjects protections We had several strategies for maintaining trust, safety, and confidentiality of criminal group members. Above all, we were transparent about our research aims, that we were speaking to other groups and the government, and that we advise the civilian government (but not the criminal justice system). We made every effort to preserve anonymity and confidentiality, while advising subjects in consent scripts of the potential limits to our ability to do so. With prison populations, we also took great efforts to ensure that our interviewees faced no pressure to speak to us. (It is worth noting, however, that our subjects were generally shrewd and powerful businessmen who in many respects are in control of their decisions and lives in the prison, if not the prison itself.)

We consulted extensively with the University of Chicago and Universidad EAFIT human subjects committees, and we obtained written support and noninterference from the Mayor, the head of the National Prison Authority, and the Colombian Minister of Justice.

\subsection{Survey data and measurement strategies}

In 2019 we surveyed nearly 7,000 residents and businesses on the degree of state and combo rule, the perceived legitimacy of both, and levels of taxation and payments to combos. The survey was representative of all 223 low- and middle-income neighborhoods in Medellín, plus nine neighborhoods bordering Medellín in other municipalities (see Figure 2). We randomly sampled 2,347 of the city's 14,600 blocks, stratified by neighborhood, then randomly sampled approximately two households and one business on each block. 
Addressing measurement error Naturally, we are concerned that citizens under-report gang activities. Several pieces of evidence suggest that survey respondents answered questions truthfully, however. First, combos are a routine part of life, and in interviews and surveys we found that most people spoke freely when interviewed in private. Second, we conducted all surveys anonymously, alone, and indoors. Third, as we discuss below, a survey experiment finds no evidence of systematic misreporting.

\section{Context and descriptive analysis}

\subsection{The state}

Medellín has 2.6 million people, with almost 4 million in the metro area. Per capita annual income is roughly $\$ 11,500$, adjusted for purchasing power parity. The city is divided into 16 urban comunas, which are themselves composed of 269 neighborhoods called barrios.

The city has a well-organized, professional bureaucracy with high fiscal capacity and broad-based public services. With a huge commercial sector, the city has ample revenues. Two main organizations are responsible for order.

The Secretariat of Security is a large civilian organization with roughly 2,500 civilian staff. It sits directly beneath the Mayor and is the city's primary organization to address issues related to security and dispute resolution. To do so, the Secretariat has several "headquarters" in each comuna. Inspecciones host officials who directly resolve community disputes through a formal, fast-track justice service. Comisarías host a wide range of family services aimed at helping citizens in legal and psycho-social issues of domestic violence, restoration of rights to children and youth, and conciliation in family law. The more common Casas de Justicia host both type of services. We refer to all as "municipal headquarters". 6

The Metropolitan Police are independent from the city government. They are part of the National Police, which is a branch of the Defense Ministry. While low-level corruption and poor responsiveness are common, the police are fairly professionalized, particularly in comparison with other Latin American countries. There are 280 officers per 100,000 people in Medellín, similar to cities like Los Angeles.

\footnotetext{
${ }^{6}$ In addition to these comuna-based services, the central Secretariat is responsible for: setting security policy and coordinating actions with the police, the prosecutor's office, the prison system, and other components of the criminal justice system; investing in security infrastructure; operating the system for emergency attention, including dispatching all emergency calls; and regulating the use of public space across the city.
} 
Figure 2: Combo census: Estimated locations, with barrio income level

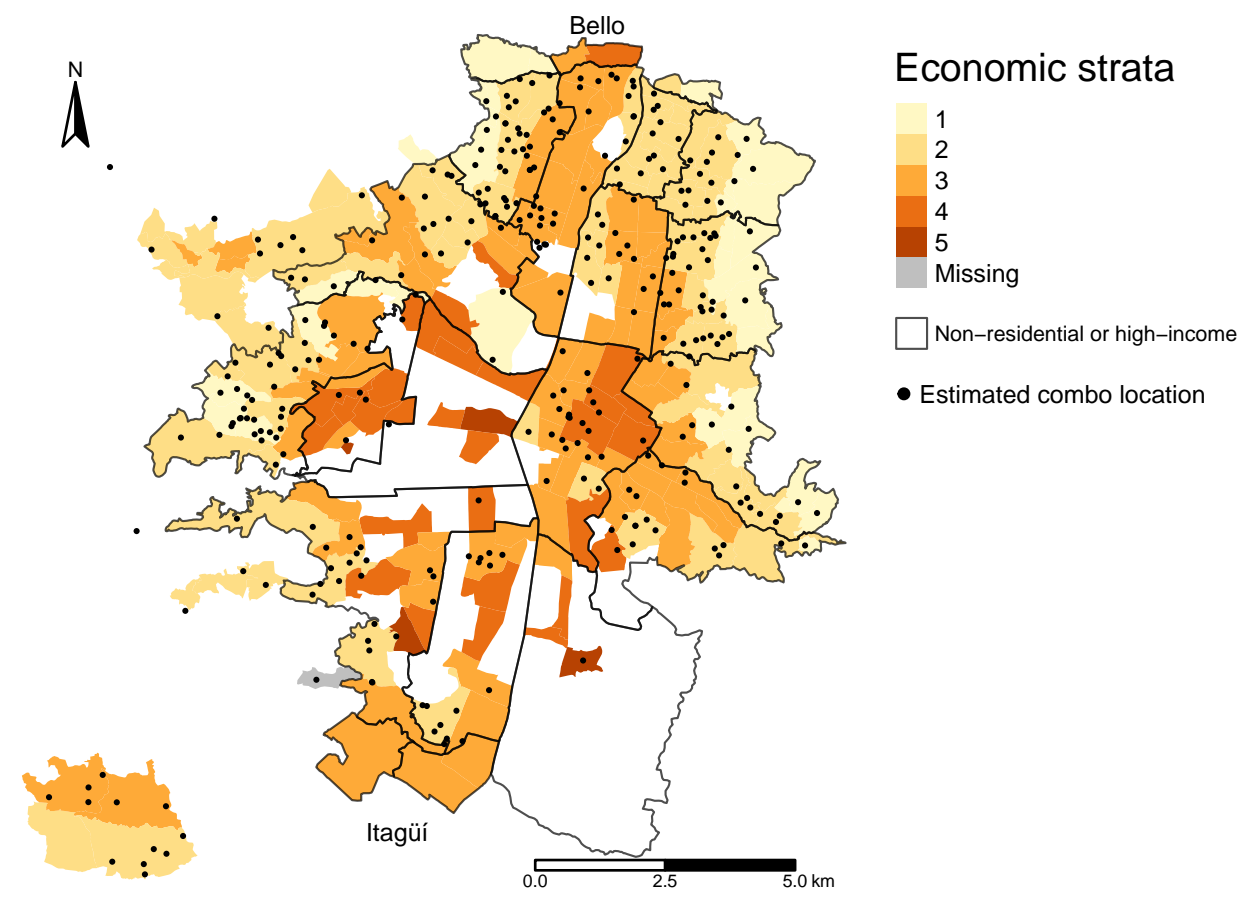

Each comuna has a police station, and the comuna is divided into a large number of cuadrantes (quadrants) - a sub-unit relevant only for the police. Each quadrant typically has 6 assigned officers who patrol on motorbike, in pairs, in 3 shifts per day. These patrol officers are greatly outnumbered, as our data suggest that there are roughly a dozen combo members for every on duty officer.

\subsection{The combo}

\section{Combo organization and operations}

Prior to this study, there was little systematic data on gangs in Medellin. Our investigations suggest that virtually every low- and middle-income residential neighborhood has a local combo. Our 2019 combo census identified approximately 380 combos in the metropolitan area (Blattman et al., 2023). We do not have detailed borders for each one, but Figure 2 plots our assessment of an intersection or other known location for each combo.

Generally speaking, combos have a core of 15 to 40 permanent, salaried members. Their territories are sometimes no more than a few square blocks, but borders are usually longstanding, well-defined, and known to most locals. Combos also tend to be long-lived. Many have been present for decades, as younger generations take over from older ones.

Most combos are small and autonomous. They are headed by a leader called a coordi- 
nador. Horizontal integration across neighborhoods is rare, because size requires more formal organization and operations, which in turn raises the risk of arrests or seizures by the police. This is a major reason why most combos have fewer than 40 members and small territories (Blattman et al., 2023).

Combo revenues come from four main sources. Practically every combo has a local monopoly on retail drug sales in their neighborhood, which occur at defined locales known as plazas de vicio. Drugs are typically their most profitable activity, though profits vary dramatically depending on whether the combo sells to local residents versus middle and high-income people from elsewhere in the city. A majority of combos also charge security fees to at least some residents and businesses, typically in return for protection services (discussed at length below). Finally, some engage in loan-sharking, debt collection, and local consumer goods markets.

Finally, Medellín's combos form the base of a pyramid of criminal organization. Above them are roughly 17 mafia-like groups sometimes called razones. Razones are typically the wholesale suppliers of drugs to the combos' street retail operations. Most combos have a longstanding business and military alliance with a razón. A small number of combos are vertically integrated into their razón. For the most part, however, combos are small autonomous firms with a long-term relational contract with the razón as their supplier.

\section{Combo governance}

Many of Medellín's combos provide order, security, and property rights enforcement, often on a private, fee-for-service basis. Examples include dispute resolution, informal contract enforcement, recovering stolen items, and private security for stores, vehicles, and other property. $^{7}$ The gangs also provide less excludable, public forms of protection, including regulating fights, disorderly conduct, and drug consumption on their blocks. At least one combo even installed security cameras for a time. Often they provide these services in exchange for weekly security fees - a kind of taxation. ${ }^{8}$

\footnotetext{
${ }^{7}$ Of course, "governance" also includes material public goods such as infrastructure, as well as collective decision-making and coordination. Our interviews and surveys found that combos rarely offer such services. Infrastructure is provided almost solely by the state, while informal leaders and elected neighborhood councils manage most local collective decisions. Instead, combos tend to specialize in services that are at least partially excludable, and those that benefit from coercive power. In the remainder of the paper, we use "governance" as shorthand for this set of protection services in which both gang and state participate.

${ }^{8}$ Even these more public goods, however, are partially excludable. For instance, combos often focus their public protection on blocks where they already have many private customers. Some provide hot-lines to those paying security fees.
} 
Expansion of gang rule in the 2000s Widespread local gang rule is a relatively recent phenomenon. Prior to 2000, Medellín's criminal gangs focused on international trafficking of drugs and there was little focus on local rent-seeking or rule. The local drug market took many years to foster, and while there are no historical data, our interviews and other research suggest that it did not take off until after 2000 (Salazar and Jaramillo, 1996; Thoumi, 2017; Martin, 2012). As we discuss below, there is evidence that gang rule and retail drug markets co-evolved.

Conflict is another reason that gang rule may have been slow to evolve. During the 1980s and early 1990s, Medellín's combos were engaged in open war with the Colombian government, and later amongst themselves. Only in the more peaceful late 1990s and 2000s did gang governance emerge, along with the turn from violence to the extraction of illicit rents in local markets, including selling protection and retail drug sales. ${ }^{9}$

Contemporary levels and variation To measure governance in 2019, we asked residents how frequently each actor responded to 17 common disputes and forms of disorder (12 from residents and 5 from business-owners). We identified these through our qualitative work. Table 2 reports scaled responses, where $0=$ Never, $0.33=$ Occasionally, $0.66=$ Frequent, $1=$ Always. We create average indexes of State and Combo governance (0 to 1), as well as the difference between them, Relative state governance, which can vary from -1 to 1 .

The average response for any service by either provider was seldom greater than 0.5 , suggesting that for residents, neither the state nor the combo are reliably responsive to disputes and disturbances. Combos are most responsive to unpaid debts, property crimes, and public disturbances. Combo involvement was somewhat lower for inter-neighbor disputes such as noise complaints and property infringements.

These averages conceal a great deal of neighborhood variation. Figure 3 maps relative state governance by barrio. In $31 \%$, residents report the combo is more responsive than the state. In others the state is dominant, though to varying degrees. Note, however, that high state governance does not imply combos are absent. Nearly every neighborhood has a strong combo presence. Some combos have chosen not to offer private protection in those neighborhoods. See Appendix Figure A.1 for variation in combo governance.

When they choose to govern, combos can be effective in many respoects. For example, $67 \%$ of survey respondents said the combo was easy to contact compared to $63 \%$ for the police and $32 \%$ for the Mayor's office. They also said the combo responded rapidly $58 \%$ of

\footnotetext{
${ }^{9}$ They exited global trafficking because: the United States limited their routes over the Gulf; the takeover of the trafficking market by overland cartels in Mexico; the defeat of Pablo Escobar's organization in the 1990s; and as a response to U.S. extradition policy in the 2000s (Martin, 2012). Nonetheless, our qualitative data suggests some razón leaders oftentimes invest in cocaine shipments but as a personal business decision.
} 
Table 2: State and combo governance and legitimacy, barrio survey averages, 2019

\begin{tabular}{|c|c|c|c|c|c|}
\hline & \multicolumn{4}{|c|}{ Frequency/Rate (0-1 Scale) } & \multirow{3}{*}{$\begin{array}{c}\text { Relative Stat } \\
\text { Governance } \\
\text { Difference } \\
(5)\end{array}$} \\
\hline & \multicolumn{2}{|c|}{ State } & \multicolumn{2}{|c|}{ Combo } & \\
\hline & $\begin{array}{l}\text { Estimate } \\
(1)\end{array}$ & $\begin{array}{l}\text { SD } \\
(2)\end{array}$ & $\begin{array}{c}\text { Estimate } \\
(3)\end{array}$ & $\begin{array}{l}\mathrm{SD} \\
(4)\end{array}$ & \\
\hline Governance Index & 0.41 & 0.27 & 0.33 & 0.29 & 0.08 \\
\hline \multicolumn{6}{|l|}{ How often they intervene when: } \\
\hline $\mathrm{HH}$ : Someone is making noise & 0.42 & 0.38 & 0.19 & 0.30 & 0.23 \\
\hline HH: Home improvements affect neighbors & 0.41 & 0.37 & 0.24 & 0.33 & 0.16 \\
\hline $\mathrm{HH}$ : There is domestic violence & 0.50 & 0.37 & 0.33 & 0.37 & 0.16 \\
\hline Biz: Someone disturbs a business & 0.50 & 0.38 & 0.36 & 0.38 & 0.14 \\
\hline HH: Two drunks fight on the street & 0.52 & 0.36 & 0.39 & 0.37 & 0.13 \\
\hline Biz: You have to react to a robbery & 0.53 & 0.37 & 0.39 & 0.39 & 0.13 \\
\hline Biz: It is necessary to prevent a theft & 0.46 & 0.36 & 0.37 & 0.39 & 0.09 \\
\hline Biz: Businesses in this sector are robbed & 0.43 & 0.39 & 0.35 & 0.38 & 0.07 \\
\hline HH: A car or motorbike is stolen & 0.47 & 0.37 & 0.41 & 0.38 & 0.05 \\
\hline HH: People smoking marijuana near children & 0.30 & 0.36 & 0.25 & 0.36 & 0.05 \\
\hline HH: You have to react to a robbery & 0.46 & 0.36 & 0.44 & 0.38 & 0.02 \\
\hline $\mathrm{HH}$ : Someone is threatening someone else & 0.41 & 0.36 & 0.40 & 0.37 & 0.01 \\
\hline $\mathrm{HH}$ : Someone is mugged on the street & 0.39 & 0.36 & 0.40 & 0.38 & -0.01 \\
\hline $\mathrm{HH}$ : It is necessary to prevent a theft & 0.39 & 0.36 & 0.41 & 0.38 & -0.02 \\
\hline HH: Kids fight on the street & 0.28 & 0.35 & 0.31 & 0.36 & -0.03 \\
\hline Biz: Someone does not want to pay a debt & 0.18 & 0.31 & 0.24 & 0.35 & -0.06 \\
\hline HH: Someone refuses to pay a big debt & 0.21 & 0.31 & 0.36 & 0.37 & -0.16 \\
\hline Legitimacy Index & 0.57 & 0.21 & 0.43 & 0.28 & 0.14 \\
\hline \multicolumn{6}{|l|}{ When solving problems in the neighborhood: } \\
\hline How much do you trust the... & 0.57 & 0.30 & 0.36 & 0.36 & 0.21 \\
\hline How fair is the... & 0.55 & 0.27 & 0.41 & 0.35 & 0.14 \\
\hline How much do your neighbors trust the... & 0.57 & 0.28 & 0.47 & 0.36 & 0.10 \\
\hline How would your neighbors trust the... & 0.59 & 0.23 & 0.50 & 0.29 & 0.09 \\
\hline How do you rate the... & 0.60 & 0.22 & 0.51 & 0.28 & 0.09 \\
\hline
\end{tabular}

Notes: Different governance questions were asked of household (HH) and business (Biz) respondents. Only households answered legitimacy questions. The survey is representative of Medellín's 224 low- and middle-income barrios, with 20-25 respondents per barrio. Governance scales correspond to: $0=$ Never, $0.33=$ Occasionally, $0.66=$ Frequently, 1 $=$ Always. Legitimacy scales correspond to: $0=$ Nothing, $0.33=$ A little, $0.66=$ Somewhat, $1=$ Very. 
Figure 3: Relative state governance by barrio, 2019
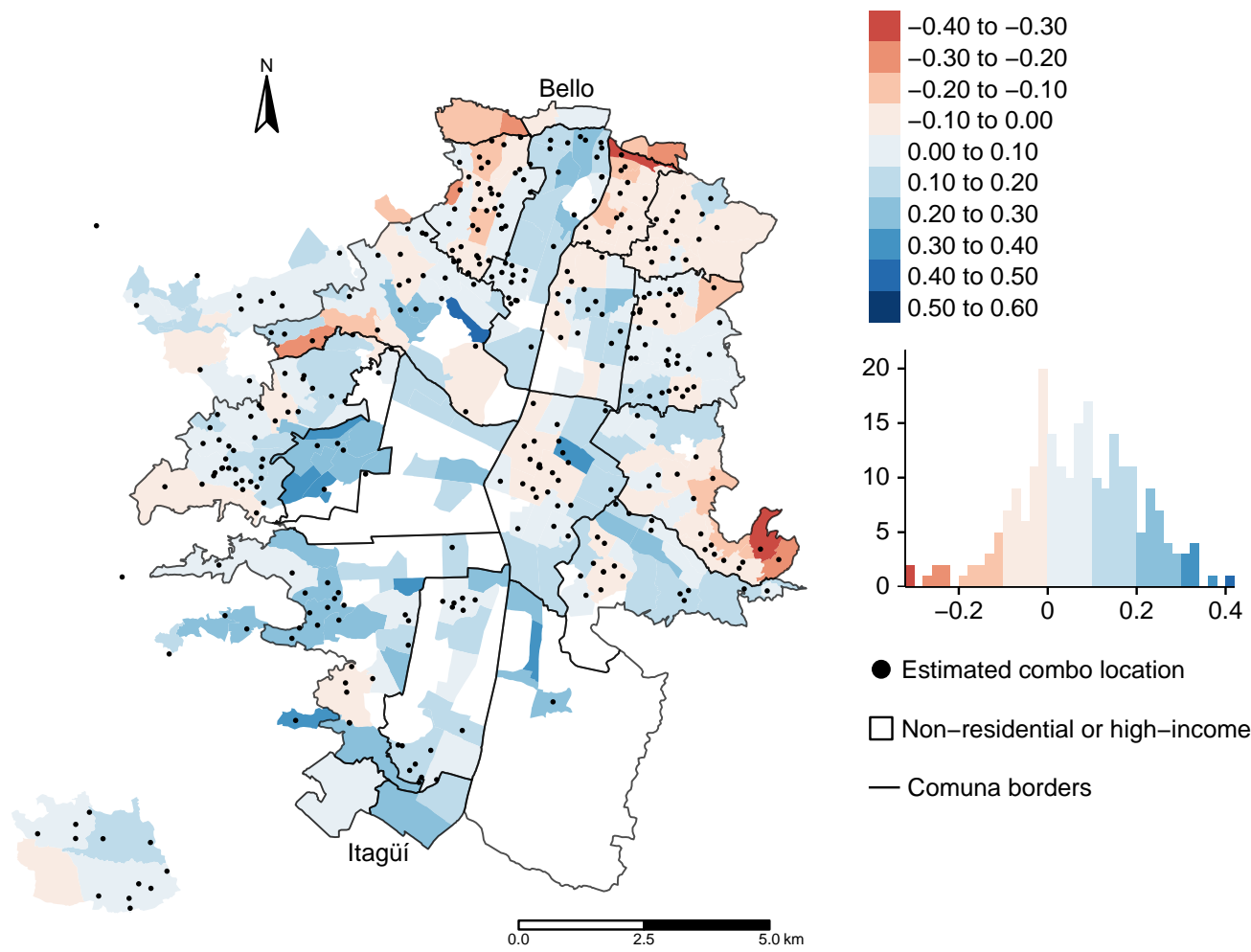

- Estimated combo location

$\square$ Non-residential or high-income

- Comuna borders

Notes: Our index of relative state governance runs from -1 (full combo governance) to 1 (full state governance). Blue indicates state governance $>$ combo governance; red indicates combo governance $>$ state governance. Each barrio's value is the average relative state governance (state-combo governance index) for all 17 items from Table 2. We did not survey high-income barrios.

the time compared to $41 \%$ for the police and $27 \%$ for the Mayor's office.

This is not surprising. With the exception of the police, the city's street-level bureaucrats are rarely available outside of business hours; offices are closed on Colombia's frequent holidays; and due to contracting peculiarities, every December to January a large proportion of city staff on contracts are not working. The combo, by contrast, is always present.

Combos have other advantages. They have more local knowledge and deeper networks than state bureaucrats, and even local police. Community leaders have good information too, but combos have organized means of coercion to enforce rules and deals. Indeed, a combo's freedom to use force can exceed that of the state. For example, they can carry out swift and sometimes violent sanctions that some residents demand, such as expelling an abusive husband from the neighborhood. Also, whereas the state and community leaders are expected to be impartial and consistent, some combos openly resolve disputes and enforce contracts in favor of those who hire them or who are most closely connected. Residents have few mechanisms for accountability or voice in shaping and enforcing combo rule. 
Figure 4: Relationship between combo governance and combo legitimacy, 2019

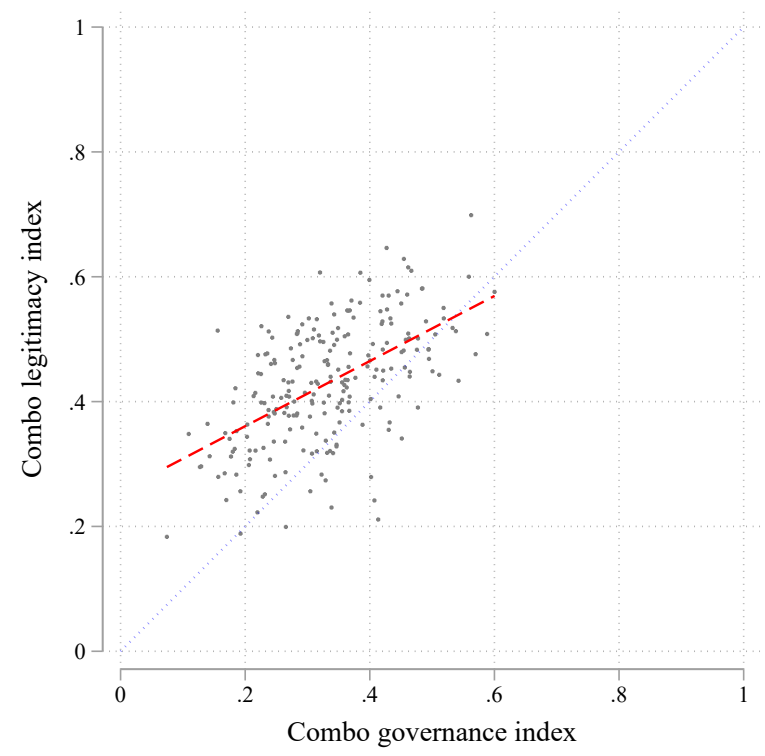

Notes: Each dot is a barrio average, and the dashed line indicates fitted values (correlation of 0.55).

We did not survey high-income barrios.

\subsection{Legitimacy}

These differences in style help explain why many residents are conflicted about combo rule. Many report they are happy to have access to both the combo and the state for protection. Just $46 \%$ of survey respondents agreed to the question that the neighborhood would be better off without the combo. Elaborating, some said they feared the vacuum of authority that might open up without this local actor. Others were simply satisfied with the work of the muchachos ("local boys"), a common term for combo members.

We asked residents (but not business-owners) about several dimensions of combo and state legitimacy: how much residents trust each actor; whether actors were fair; whether residents were satisfied with each actor; and whether residents thought their neighbors trust and are satisfied with each actor. We averaged these responses into unit indexes for state and combo legitimacy. Table 2 reports barrio averages. Residents rate their trust and satisfaction of the combo lower than the state, although the difference is not always large (see Appendix Figure A.2). Not surprisingly, there is a tight correspondence between combo governance and legitimacy, as illustrated in Figure 4. 


\subsection{Why do combos govern?}

Our interviews yielded three main motives for gang rule. Two we anticipated: direct revenues from protection, and intrinsic rewards from ruling. The third - indirect benefits of governance on drug retailing - emerged from our conversations unexpectedly.

\section{Motive 1: Protection as a business line}

First, for some combos, protection services are a business line that yields modest but important revenue. For services such as debt collection or dispute resolution, combos commonly charge on a fee-for-service basis. ${ }^{10}$

Revenues from other services, such as security and protection for homes and shops, are akin to semi-voluntary taxes or a subscription. Residents and businesses typically call this tax a pago por la vigilancia ("security" or "surveillance fee") or, more colloquially, a vacunaliterally, a vaccine. Among the combos where we have internal organization data, most organize vacuna collection and protection services as a specialized unit with dedicated staff, reporting to the coordinador.

To our surprise, however, most combos tax only a fraction of local businesses and residents. In our survey, $85 \%$ reported that the combo charges vacunas in their neighborhood, typically weekly. But within these communities, only a quarter of businesses and a tenth of residents reported being charged this tax themselves. Figure 5 shows that the share of people who report that they or others in the neighborhood pay regular security fees is strongly positively correlated with combo governance levels - close to the 45 degree line. (Our survey experiment, discussed below, suggests these reporting rates are roughly accurate.)

Moreover, vacunas are relatively modest. Among those who pay, median weekly amounts were about US $\$ 1$ for residents and US $\$ 2$ for businesses - roughly $3 \%$ of business profits and $1 \%$ of sales at the median. ${ }^{11}$ While $89 \%$ of businesses said they disapprove of vacunas, just $27 \%$ of businesses said that vacunas were too high. By comparison, municipal taxes on these enterprises are about $6 \%$ of profits, and $54 \%$ said they were too high. ${ }^{12}$

\footnotetext{
${ }^{10}$ As one community leader told us: "If a couple starts fighting, they [the gang] come to a kind of trial and fine them. It is the same with the problems between neighbors; they set fines of 100,000 [pesos]" Community Leader 14/17, interview 1/1 [08/06/2020]. Another leader explained how "if you fight with someone, regardless of whether you provoked it or not, you must pay between 100,000 and 500,000 [pesos], depending on how serious the fight is. They decide what price to impose. There are also fines for theft. For example, something that happens a lot: a neighbor steals some plants from me, so she must buy or return those plants and also pay the fine to them. The price of the fine depends on what was stolen." - Community Leader $4 / 17$, interview $1 / 2[02 / 22 / 2020]$.

${ }^{11}$ Identifying a tax rate seemed to be relatively straightforward. Typically, a junior member of the relacionista staff observes a business for a few days, using the store characteristics and counting the number of customers per day to select an appropriate tax rate.

${ }^{12}$ As with any tax, we should not exaggerate the voluntary nature of the vacuna. While in some places
} 
Figure 5: Relationship between gang governance and vacuna payments, 2019

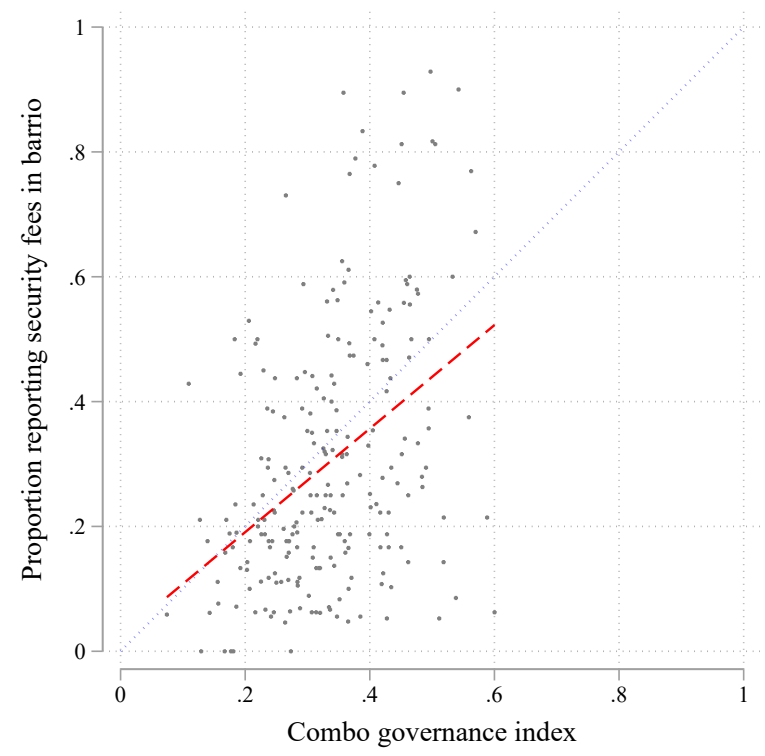

Notes: Each dot is a barrio average, and the dashed line indicates fitted values (a correlation of 0.42).

We did not survey high-income barrios.

The remaining two motives may help to explain the low rates and incidence of combo taxation.

\section{Motive 2: Intrinsic rewards}

Power, authority, and the loyalty of subjects can also be their own reward. Some combo leaders reported taking pride in ruling, or simply enjoying the status and moral legitimacy it offers. As one said, "Personally, doing good work feels good. You can be the worst bandit, but you can also have a good heart of your own."13

Some also describe governance as a moral obligation or social duty to their community. Many combos emerged in the 1980s as local defense forces fighting left-wing militias affiliated with rural guerrilla movements. Today, most gangs in Medellín retain a socially conservative and anti-communist ideology. Many of the leaders we met saw themselves as responsible for upholding moral codes, protecting women and girls, and preserving conservative social mores. Others described themselves as critical "anti-subversivos"—-bulwarks against socialism. They resent the lack of recognition of their contribution to Colombia's civil war.

they are discretionary, and in others payments are an obligatory but generally-accepted tax, in some neighborhoods they resemble outright extortion. About half of respondents reported that refusing to pay the vacuna would result in threats or assaults. At the same time, that implies half did not expect coercion. In these cases, respondents said that the combo would simply stop providing them security if they failed to pay.

${ }^{13}$ Criminal Group Member 6/40, interview 2/3 [02/11/2020]. 
Combos may derive utility from the status that their authority confers. In addition to pride and any appreciation of community respect, some of our interviews suggest respected combos may enjoy easier access to women.

\section{Motive 3: Indirect impacts on other business lines}

The final and potentially most important motive for governing is that it helps protect the gang's physical security and illicit income from competitors and, perhaps more importantly, police.

First, providing order means that the state enters combo's core territories less often. As one combo leader put it, "There is a good relationship with the people," and therefore, "it is easier to bring order in the sector and so the police do not have to come around." 14 When police respond to service calls, it can scare off drug buyers, require a bribe to the officers, or increase the risk of a seizure. If crime and disorder are high, moreover, local police feel pressure from superiors to crack down. One active combo member offered a vivid example: "The police station is across from our headquarters and they never bother us. They know where our drug corners are and who works there. That's why it's important to keep the neighborhood calm: if nothing bad happens, the police don't squeeze us and let us work."15 Combos are especially keen to avoid major disputes and serious crimes, because it means that specialized police and municipal units enter their territory - units who are not from the neighborhood, and who are difficult to intimidate or corrupt.

A second reason to provide order, leaders told us, is to provide the cooperation or even the loyalty of residents. Loyal residents are less likely to inform on combos to police. Asked about the benefits of governing, one combo member responded that they do it so that, "the neighbors love us, do not rat us out to the cops, watch us doing our stuff and do not interfere, and let us know when the police are coming."16 Finally, as one public prosecutor told us, "They're very interested in winning over the community. That's why it's so hard to get witnesses against them." 17

In some cases, this loyalty can even lead some community members to help protect the combo from the authorities. "The community shields you according to your behavior," explained one leader. "If you do not have the community in your hands and at your back, you have nothing. That is who takes care of you." ${ }^{18}$ As another explained, "Caring for the neighbors gives a criminal more security. When the community feels comfortable and

\footnotetext{
${ }^{14}$ Criminal Group Member 6/40, interview 2/3 [02/11/2020].

${ }^{15}$ Criminal Group Member 5/40, interview 1/2 [10/09/2019].

${ }^{16}$ Criminal Group Member 8/40, interview 1/1 [12/30/2020].

${ }^{17}$ Official $12 / 17$, interview $1 / 5$ [10/16/2019].

${ }^{18}$ Criminal Group Leader 13/30, interview 1/2 [05/02/2019].
} 
grateful, they open their houses, so that if you have to hide from the police, the community is going to welcome you. The community goes out to defend you." ${ }^{19}$

Third, combos also face rival criminal-market entrants, and the benefits of establishing order or loyalty extend to inter-gang competition as well. Even where combos enjoy firm local monopolies on crime and extortion, they must defend these against local coups, neighboring combos, and sometimes their razones (which could invade or sponsor a coup from combo or non-combo youth from the neighborhood). Insufficient neighborhood order or other dissatisfaction with local combo rule could lead to collaboration with rivals. Such coups and uprisings are unusual, but this could be an equilibrium outcome.

These motives - preventing police and rival entry and fostering loyalty - may explain some of the puzzling patterns we observe in the protection market. Chief among them is the modest level of vacunas and the relatively low rates of vacuna incidence in some neighborhoods.

Another pattern consistent with loyalty-seeking is that few of the combo leaders we spoke to saw protection as a highly profitable business line. Some said they provided the service at a discount because of the indirect benefits. One former gang member described fees and fines for dispute-resolution services as a way to limit demand and deter disputes, rather than as a money-making strategy. ${ }^{20}$

A final pattern consistent with loyalty-seeking is that combos avoid charging businesses whose ability to pay is low or whose loyalty is more fragile. For instance, when asked why some grocers were targeted and others were not, one combo member explained that some were more likely to denounce the combo to the police if pressed to pay, and it is better to keep the population loyal. ${ }^{21}$ Another explained that "There is no fixed fee; it is voluntary." He described how, when a new business opens, the combo talks to the owner and agrees on the weekly vacuna based on the size and type of business. If the business is doing badly, however, the combo does not demand payment. "We are here to help," he explained. ${ }^{22}$

In contrast, extortion of busses can be far more extreme. This may be the exception that proves the rule. Passenger bus lines are small, cash-heavy private businesses with many small owners. Most combos extort busses along at least one route through their neighborhood. They charge drivers heavy fees, and seldom provide services in return. This is because, typically, both drivers and owners come from outside the combo's territory. ${ }^{23}$

\footnotetext{
${ }^{19}$ Criminal Group Member 6/40, interview 2/3 [02/11/2020].

${ }^{20}$ Criminal Group Leader 24/30, interview 5/5 [12/14/2020].

${ }^{21}$ Criminal Group Leader 23/30, interview $2 / 2$ [12/28/2020].

${ }^{22}$ Criminal Group Leader 1/30, interview 1/6 [06/20/2019].

${ }^{23} \mathrm{An}$ interesting aside: bus routes typically pass through many territories, and combos have solved the common-pool resource problem by developing a collective norm whereby the combo at the bus' point of origin holds extortion rights.
} 
Our hypothesis is that combo violence and extraction are disciplined by the need for local collaboration only.

Several correlations are consistent with this indirect motive for governance. Appendix Table A.1 reports simple correlations between block combo governance levels and neighborhood characteristics. We observe more combo governance near high drug value areas (proxied by the value of police drug seizures from 2014-19). We also see more governance close to their headquarters - both the combo's and their affiliated razón's. There is also more governance when there are more competing combos in the vicinity, in poorer neighborhoods, and in neighborhoods on the higher slopes of the mountainsides - patterns consistent with both the economic development and strategic response mechanisms. Of course, none of these are causal relationships, and so we have to take them with caution. Rather, the focus of the remainder of this paper is how the presence of state protections services affects combo governance.

\section{An alternative strategy: Corrupting the state}

A natural question is why the combos need to govern to avoid police interference. Why not simply buy off the police? This is indeed an alternative strategy. Every neighborhood has 6 police assigned to patrol - three pairs that patrol in 8-hour shifts. Qualitatively, paying off these local patrols is commonplace. In principle, in response to state presence, combos can allocate effort to co-opt local police rather than govern civilians. If so, this would moderate any strategic complementarities between state and gang rule.

At the same time, this corruption has serious limits. The police are a national institution, and the senior ranks are rotated regularly. Thus, to our knowledge, no combo or razón has been able to buy significant and persistent influence above the local level.

At the local level, moreover, patrols are still held to targets and quotas by the station chief, and they must respond to citizen complaints and calls. Thus they cannot give a combo or drug plaza immunity. More importantly, precisely because the city is aware of the issue of corruption, most drug seizures, raids, and major arrests are planned and executed by specialized police units supervised by the centralized command and the Secretary of Security. These authorities are generally beyond the ability of most combos to buy. As one former prison-gang leader explained, "there is always a police presence, but combos strike non-interference deals with the regular beat cops. When public order gets disrupted, the police must act and officers not part of the deal arrive. The area becomes visible and combos' activities become more vulnerable." ${ }^{24}$

\footnotetext{
${ }^{24}$ Criminal Group Leader 24/30, interview 5/5 [12/14/2020].
} 


\section{Conceptual framework}

To structure these hypotheses, we use a simple model of imperfect competition to show how gang and state rule could be either strategic substitutes or complements. The substitutes view is consistent with a gang's optimal response under duopolistic competition when protection is an isolated business line. We illustrate with Cournot competition, where each side chooses the quantity of protection services and let prices clear the market (though any model of imperfect competition produces a similar result). ${ }^{25}$ We then introduce into the model externalities from governing.

We simplify the presentation in two ways. First, we do not model the state's full objective function or its optimal policy choice because we are mainly interested in understanding the gang's best response to variations in state rule. Second, both gangs and the state are deciding how to allocate resources within their territory but we abstract away from this reallocation decision. Altogether, the approach taken here is intended to motivate the quasiexperimental analysis and discussion of mechanisms, in which localized variation in state rule around new administrative borders is essentially accidental. We want to understand under what circumstances the other duopolist would respond by increasing quantities produced.

\subsection{Cournot competition in the market for protection}

Consider a gang $g$ and a state $s$ offering distinct but substitutable services to residents of a block - in quantities $q_{g}$ and $q_{s}$, at a constant marginal cost of production $c_{i}$. We can write each organization $i$ 's utility function as:

$$
V_{i}=p_{i} q_{i}-c_{i} q_{i}
$$

Price is determined by a linear inverse demand curve:

$$
p_{i}=a_{i}-\beta q_{i}-\gamma q_{j}
$$

where $\gamma \in(0,1]$ implies the $q$ are substitutes and $\beta>0$ implies downward-sloping demand.

We are interested in whether gang rule is crowded in or out when there is an exogenous increase in state governance on the block: $\frac{\partial q_{g}^{*}}{\partial q_{s}}$. We derive each organization's best response

\footnotetext{
${ }^{25}$ Appendix B shows how the gang's response would be similar in other forms of imperfect competition, including a model of stationary bandits competing to provide public goods. In modeling duopolistic competition, however, note that we abstract away from competition between combos. We do this in part because gangs are insulated from territorial competition by the razones, who protect gang property rights.
} 
function, equilibrium values of $q_{g}^{*}$ and $q_{s}^{*}$, and comparative statics in Appendix B, showing:

$$
\frac{\partial q_{g}^{*}}{\partial q_{s}}=-\frac{\gamma}{2 \beta} .
$$

So long as the two services are not complements, this comparative static implies that increases in one duopolist's supply of protection will reduce the other's - what we call "crowding out".

\subsection{Additional benefits to governing}

Above, gang leaders described additional benefits to governing beyond the money it brings in as a business line. We summarize these diverse motives by adding a single, stylized term, $\rho\left(q_{i}, q_{j}\right) \pi_{i}$, to the players' objective functions:

$$
V_{i}=p_{i} q_{i}-c_{i} q_{i}+\rho\left(q_{i}, q_{j}\right) \pi_{i}
$$

Set up this way, $\pi_{i}$ is the return to full control of the block. For example, $\pi_{g}$ includes the illicit rents from unimpeded retail drug sales, but it also includes non-material benefits, such as status, access to women, and other intrinsic rewards from loyalty and rule. The state has its own distinct $\pi_{s}$ in the form of electoral rewards, achievement of policy aims, or preferences for dominance and citizen loyalty.

Meanwhile, $\rho(\cdot)$ scales each organization's ability to capture, retain, or enjoy these benefits. We can think of it as the share of $\pi_{i}$ each player enjoys, one that is increasing in own

governance and decreasing in the other's, such that: $\frac{\partial \rho\left(q_{i}, q_{j}\right)}{\partial q_{i}}>0>\frac{\partial \rho\left(q_{i}, q_{j}\right)}{\partial q_{j}}$. Importantly, however, we remain agnostic about whether $\rho(\cdot)$ exhibits increasing or decreasing returns to own and other's governance provision.

The elasticity of gang governance to state governance now becomes:

$$
\frac{\partial q_{g}^{*}}{\partial q_{s}}=\frac{\lambda \pi_{g}-\gamma}{2 \beta-\delta \pi_{g}} .
$$

where $\lambda=\frac{\partial^{2} \rho\left(q_{g}, q_{s}\right)}{\partial q_{g} \partial q_{s}}$ represents the cross-partial derivative between gang and state governance, and $\delta=\frac{\partial^{2} \rho\left(q_{g}, q_{s}\right)}{\partial q_{g} \partial q_{g}}$ reflects the rate of increasing or decreasing returns to governing.

Equation 5 helps us to identify several channels by which more state governance could crowd in gang rule.

Case 1: Strategic response to state rule by the combo $\left(\lambda \pi_{g}>\gamma\right)$ This case corresponds the closest to our gang leader interviews. When the state increases protection, they 
threaten the gangs' share of rents and non-material benefits, $\rho\left(q_{g}, q_{s}\right) \pi_{g}$. The cross-partial derivative, $\lambda$, will be positive when the gang has more-than-proportional returns to increasing its own rule in response to the state's services on the block. This could arise, for example, from a gang leader who values dominance, or who is averse to losing status. Alternatively, we could think of $\rho(\cdot)$ as a contest success function for control of the block's illicit markets, with governing akin to arming. For many such functions and ranges of relative "armament" (loyalty-inducing $q_{g}$ and $q_{s}$ in our setting), the optimal response to an increase in opponent's arming is to increase one's own arming, especially when one is strong to begin with (e.g., Skaperdas and Syropoulos, 1996; Konrad and Skaperdas, 2012).

Any $\lambda>0$ will attenuate the state's attempts to crowd the gang out. The larger are $\lambda$ and $\pi_{g}$, and the more differentiated are gang and state governance services (lowering $\gamma$ ), the more likely that gang and state rule are strategic complements on the block, where $\lambda \pi_{g}>\gamma$.

All this assumes that the denominator is non-negative, which is the case when gangs have diminishing returns to their own governance. The alternative brings us to the next case.

Case 2: Increasing returns to a gang's own level of governance $\left(\delta \pi_{g}>2 \beta\right)$ Given downward-sloping demand $(\beta>0)$, the denominator in Equation 5 will be negative only if gangs enjoy large increasing returns to their own governance. This could arise, for instance, if residents reward protection with loyalty at increasing rates. While not impossible, increasing returns should not be assumed, and we saw no evidence of them. Generally, therefore, we expect diminishing returns to governance, making combo strategic response (Case 1) the more plausible of this pair of mechanisms.

Finally, in addition to these two cases, there is a third possible way that we could observe complementarities between state and gang rule.

Case 3: State rule generates growth and increases demand for governance In principle, an increase in state protection could raise the number and value of transactions in the local economy, thereby increasing demand for governance in general and gang governance in particular. This is a common feature of the political economy literature on stationary bandits, where a state monopolist has incentives to provide public goods to grow the very market they will later tax (Olson, 1993; McGuire and Olson, 1996; Grossman, 1996).

In our Cournot example, we can model endogenous growth through the demand curve in Equation 2, writing $a_{i}$ as an increasing function of $q_{s}$. The important implication is that this can produce crowding in $\left(\frac{\partial q_{g}^{*}}{\partial q_{s}}>0\right)$ independent of the forces in Cases 1 and 2 (see Appendix $\mathrm{B})$. 
Note, however, that this demand effect would have to be quite large to overcome the crowding out that arises from normal duopolistic competition. Moreover, not all models make this prediction about endogenous demand. For instance, the prediction reverts to crowding out if we move away from a traditional model of duopoly to a model of stationary bandits competing to provide public goods for taxes (see Appendix B.2).

\subsection{Accounting for variation in Medellin}

This model can help us understand some of the variation in Medellín. One is the variation within low- and middle-income neighborhoods (where gang presence is universal). The other is the contrast between high-income neighborhoods and the rest of the city.

The absence of gangs and gang rule form high-income neighborhoods suggest that it is possible to crowd our criminal organizations and governance. These neighborhoods are wealthy enough that there is presumably a high level of demand for governing transactions, yet criminal groups seldom supply this service. One possibility is that it is not especially profitable to physically control these territories - that is, $\pi_{g}$ is low. This could arise if the wealthy are willing to travel to purchase their drugs, and physical presence and control is less necessary. A more likely case is that $\lambda$ and $\delta$ are small-the gang has low returns to investments in arming when the state is especially strong (that is, when there are very high initial levels of $q_{s}$ ). This could happen if the state disproportionately prized these neighborhoods for either legitimacy or its own rents and tax revenues.

This is speculative, and the main focus of this paper is variation within low- and middleincome neighborhoods where the initial levels of state capacity are more modest, and where control of the neighborhood is meaningfully contested. This is an important scope condition for the analysis to follow.

\section{$5 \quad$ Empirical strategy}

\subsection{Medellín's new jurisdictional borders}

To test the effect of state presence on combo activities, we identified a natural experiment that created discontinuous jumps in the distance to local state protection. In 1987, Medellín's elected council divided the city into 16 areas called comunas. Previously, the city was divided into 6 such areas. The new policy subdivided each into 2-3 smaller units, producing 13 new internal borders.

This comuna subdivision changed the jurisdiction of the state's security and justice apparatus only, but no other government services. Five services are deployed within these 
borders. From the Secretariat of Security's local headquarters, there is dispute resolution through fast-track justice services, and family services discussed above. From the National Police, there are: patrolling services, attention from specialized units (such as drug squads or homicide investigations); and crime reporting, with the local police headquarters being the principal locale.

All other government services are provided at the city or the barrio level. Schools, health services, and infrastructure are organized at the city level, for instance, and residents can access them irrespective of their address (i.e., anyone can cross a comuna border to attend their preferred school or clinic). Meanwhile, local assemblies and their budgets are organized at the barrio level, and barrio borders were unaffected by the 1987 reform.

Figure 6 displays a map with original and new borders, as well as historical police stations and municipal headquarters. ${ }^{26}$ In 1987, the city had 15 full-service police stations and 37 municipal security and justice agencies that provide dispute resolution and family services. They increased this to 39 shortly as a part of the reform. These 54 historical headquarters represent the initial allocation of state services, and we focus on these. Throughout this period, the average number of police and dispute resolution officers remained relatively stable.

\subsection{Calculating block pairs and the treatment variable}

Our unit of analysis is a nearby block pair - one on each side of the new border. ${ }^{27}$ The new border shifted one of those blocks further from their prior headquarters - a "shock" to state distance. Before the new border, blocks were about 1,000 meters from their headquarters, and the border shifted one 400 meters further away at the median - a $40 \%$ change. Our treatment variable is this shock - the difference in distance to state security headquarters between two nearby blocks, $i$ and $j$, that results from the introduction of a new border. We call this distance shock $\Delta d_{i j}$.

To simplify the interpretation of the results, especially the heterogeneity analysis, it is useful to orient the shock so that a rise in $\Delta d_{i j}$ implies getting closer to the state headquarters. $^{28}$ We frame the analysis as the effect of being assigned from a block with a relatively lower allocation of state attention to one that is more proximate, and potentially receives

\footnotetext{
${ }^{26}$ We used phone books, satellite images, visits to the city and police archives, and visits to city and police infrastructure to document locations, openings, and closures. All comunas had at least one police station or municipal headquarter in 1995 , and so we can construct a $\Delta d_{i j}$ measure based on this historical presence.

${ }^{27}$ To create these nearest-neighbor block pairs, we use our representative sample of 2,066 city blocks from 2019. For each surveyed block, we calculate a matrix of distances to every other surveyed block. We then match each block $i$ with the closest block $j$ in the closest comuna (accounting for elevation changes). For each block, we then calculate the average distance to the comuna's historical police and municipal security headquarters.

${ }^{28}$ This merely changes the sign of any estimates, not the coefficient or standard errors.
} 
Figure 6: Surveyed blocks, historical state security headquarters, and pre- and post-reform comuna borders

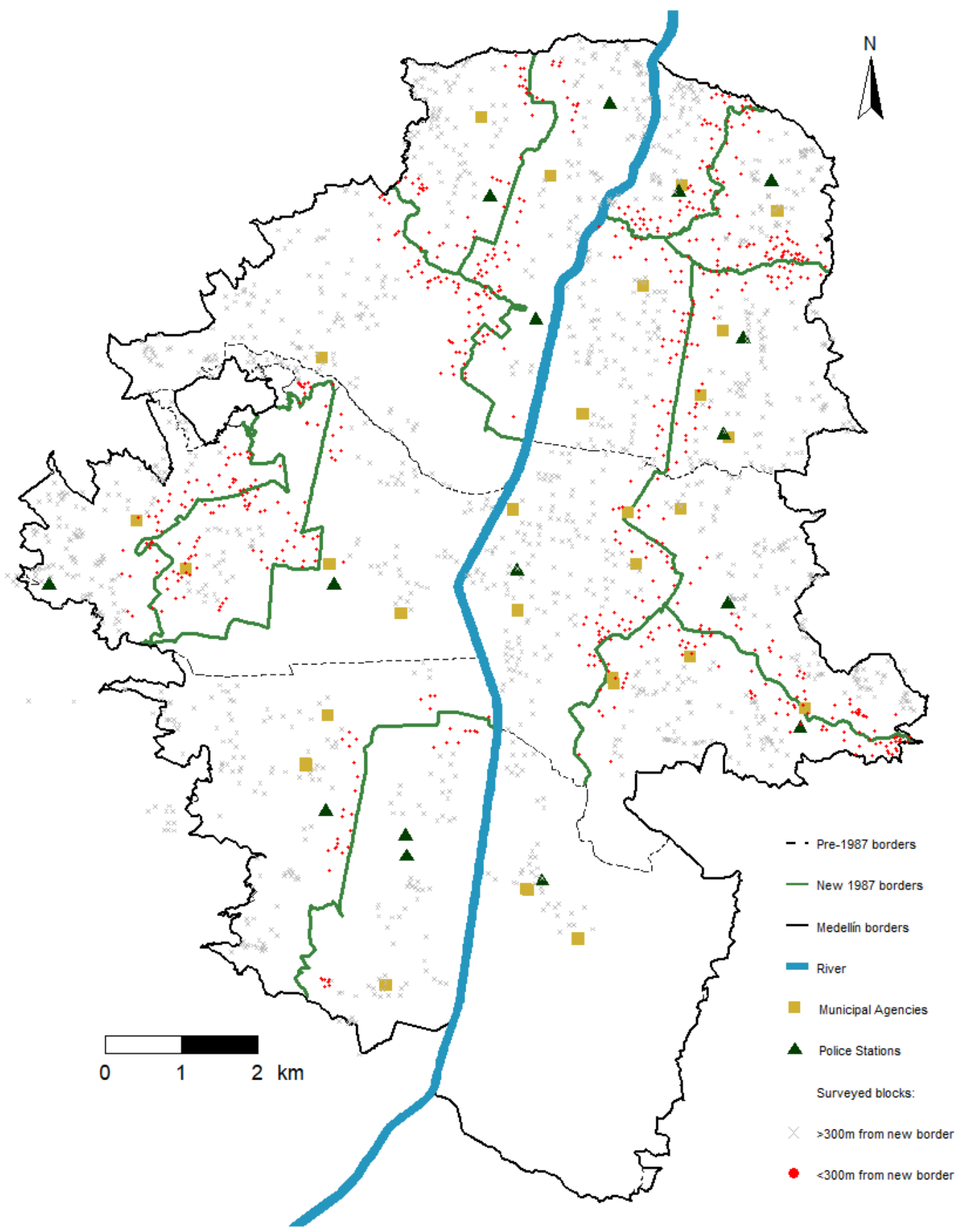

Notes: Gold squares represent municipal dispute-resolution providers; green triangles are police stations. The dotted lines represent the old comuna borders, the solid green line represents the new borders, and the black line indicates Medellín's municipal boundaries. The blue center line shows Medellín's river. Surveyed blocks are indicated as red dots and grey crosses, where the red dots indicate being in the quasi-experimental sample (within 300 meters of a new border that is not a natural boundary, such as a mountain crest). 
Figure 7: Distribution of differences in the distance to municipal agencies between paired blocks within 300 meters of the new comuna borders

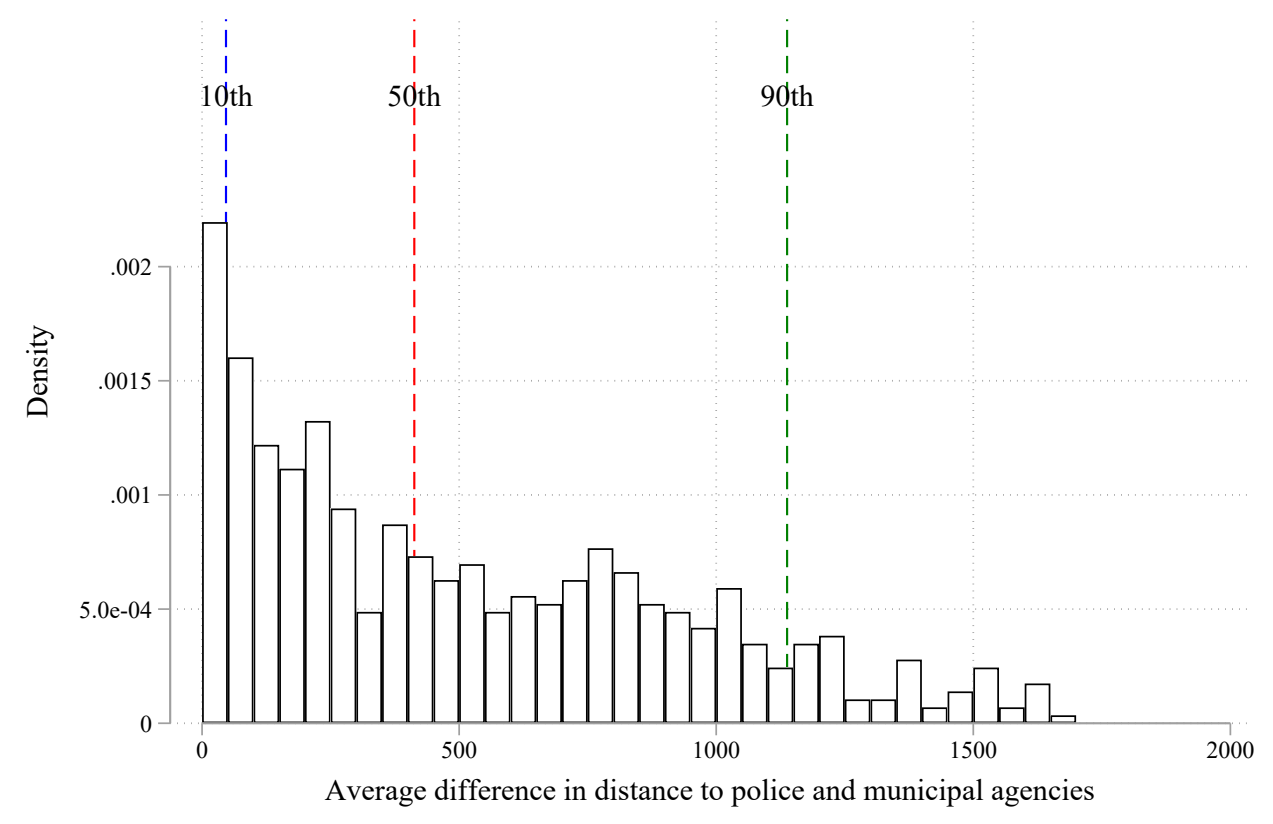

Notes: Vertical lines represent the 10th, 50th and 90th percentiles.

greater services.

We limit our sample to pairs where both blocks are within 300 meters of one of the new borders, excluding all borders that run along natural boundaries (such as impassable mountain ridges). We tested several pairing algorithms, as well as 200- and 100-meter bandwidths, and below show that results are generally robust to different approaches.

Figure 6 highlights these eligible blocks in red, and Figure 7 displays the distribution of $\Delta d_{i j}$. At the 10th percentile, a block is 40 meters relatively closer to the state, at the median it is 402 meters, and at the 90th percentile is 1,129 meters closer. The standard deviation is about 428 meters (similar to the median change).

\subsection{Identification}

We are interested in whether the distance shock $\Delta d_{i j}$ leads to differences in block-pair outcomes $\left(\Delta Y_{i j}\right)$ three decades later. To identify this, the key assumption is that the only thing that changes discontinuously at the border is proximity to comuna-based state services, proxied by $d$ (Keele and Titiunik, 2015). This would be violated if there were other systematic differences between the paired blocks, $\Delta X_{i j}$, correlated with both $\Delta Y_{i j}$ and $\Delta d_{i j}$.

This is the advantage of the border natural experiment. Consider a potential confounder 
$X$, such as the distance to local business agglomerations. For example, we might expect businesses to locate themselves close to state protection services. Combos might also choose to govern near these clusters of commerce and the state. This would confound a simple cross-sectional regression of combo governance on distance to the state. Once we look at cross-border differences, however, this confounding should dissipate. Paired blocks should be equally close to business agglomerations, not only because the two blocks are close to one another, but also because they can access and benefit from the economic activity regardless of the border. We can test this assumption by looking at the relationship between $\Delta d_{i j}$ and any potential confounders $\Delta X_{i j}$ that we observe. We return to this below.

Non-uniform direction of treatment and clustering If treatment was assigned uniformly, the border natural experiment would be akin to a clustered randomized trial with just 13 clusters. That is not the case, as none of the 13 borders assign treatment in a uniform direction. We illustrate in Figure 8. On the far left, the new border assigns block 1 to a more distant headquarters because its pair (block 2) is closer to its comuna headquarters. On the far right, the same border assigns a block on the opposite side (block 6) to a more distant headquarters. Distance shocks $\Delta d_{1,2}$ and $\Delta d_{6,5}$ have similar magnitudes, but the border does not consistently assign blocks on one side to treatment or control.

Moreover, the magnitude of the shock also varies along the border. Any block pair in between those on the far left and right will receive a much smaller shock, as illustrated by blocks 3 and 4 . This is partly due to irregular border lines, but it is mainly because of the positioning of state headquarters on either side.

This switching of treatment directions and varying magnitudes arguably creates treatment clusters along border segments, as Figure 8 also illustrates. We calculate clusters of nearby block-pairs with the same treatment direction via a simple algorithm: we first divide block-pairs by direction of treatment (for a minimum of 2 clusters per border) then run a $k$-means algorithm $(k=4)$ to find up to 4 points that minimize distance to each subsample. We constrain these 4 clusters to be at least 500 meters apart. This approach identifies 42 clusters in all-roughly 3 per border, and about 14 block pairs per cluster. Our main regressions, including balance tests, cluster standard errors at this level.

Balance If our identification assumptions are correct, then the pair difference in any confounder, $\Delta X_{i j}$, should be small and uncorrelated with $\Delta d_{i j}$. This balance test is our setting's analogue to a regression discontinuity plot with covariates unaffected by treatment - an indirect test of the continuity assumption.

Note that a traditional graphical plot is impossible because treatment is not discrete; our 
Figure 8: Stylized illustration of variation in both treatment intensity and which side of the border is treated

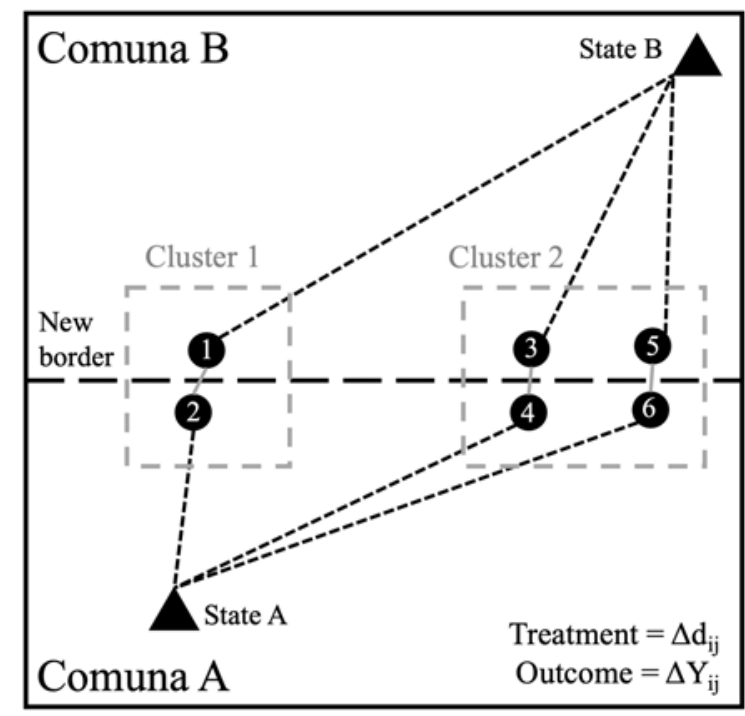

Notes: On the left, the new border assigns block 1 to a more distant headquarters than its pair (block 2). On the right, the same border assigns a block on the opposite side (block 6) to a more distant headquarters. The shocks $\Delta d_{1,2}$ and $\Delta d_{6,5}$ are similar in magnitude, but the direction of the treatment varies along the border. In light gray we illustrate the two clusters.

unit of analysis is a matched pair rather than a single street block; the borders do not assign treatment in a single direction; and (most importantly) the new borders assign a distinct and continuous distance shock to each border-pair.

Table 3 reports the continuous balance test for observed covariates: distance to other state services (such as schools and health centers); distance to business agglomerations; and a range of block-level geographic and demographic characteristics from the 1993 census. $^{29}$ Column 1 reports means and standard deviations for all blocks within 300 meters of a new border. Column 2 reports the main identification test-whether differences in paired blocks correlate with $\Delta d_{i j}$. Each estimate comes from a separate regression of the covariate on a distance shock controlling for border fixed effects and each block's distance to a common fixed point on the border, clustering standard errors at the level of the 42 groups of nearby block-pairs (see Equation 6, below).

We observe economically small and statistically insignificant differences across all covariates but one - the existence of the block in 1985. Only one in 17 covariates shows any imbalance: blocks closer to state services were slightly more likely to have been built since 1985. We control for all covariates listed as a precaution in our main specification, but (as

\footnotetext{
${ }^{29}$ Earlier rounds were not available, and though these data were collected slightly after treatment began, we nonetheless expect them to change only negligibly at the border.
} 
Table 3: Balance test: How block pair differences vary with $\Delta d_{i j}$

\begin{tabular}{|c|c|c|c|}
\hline \multirow{3}{*}{ Effect on $\Delta X$} & & $\begin{array}{l}\text { Effect of moving } \\
100 \mathrm{~m} \text { closer to state }\end{array}$ & $\begin{array}{c}\text { As } \% \text { of } \\
\text { sample mean }\end{array}$ \\
\hline & $\begin{array}{c}\text { Subsample } \\
\text { Mean } \\
\text { (SD) }\end{array}$ & $\begin{array}{l}\text { Estimate } \\
\quad(\mathrm{SE})\end{array}$ & Estimate \\
\hline & (1) & (2) & (3) \\
\hline Median age (1993) & $\begin{array}{l}25.78 \\
(6.17)\end{array}$ & $\begin{array}{l}0.180 \\
(0.186)\end{array}$ & 0.7 \\
\hline Share of population no education (1993) & $\begin{array}{l}0.04 \\
(0.06)\end{array}$ & $\begin{array}{l}-0.000 \\
(0.002)\end{array}$ & -0.5 \\
\hline Share completed primary ed. (1993) & $\begin{array}{l}0.82 \\
(0.10)\end{array}$ & $\begin{array}{l}-0.003 \\
(0.004)\end{array}$ & -0.4 \\
\hline Share completed secondary ed. (1993) & $\begin{array}{l}0.46 \\
(0.20)\end{array}$ & $\begin{array}{l}0.000 \\
(0.005)\end{array}$ & 0.1 \\
\hline Share completed higher ed. (1993) & $\begin{array}{l}0.10 \\
(0.11)\end{array}$ & $\begin{array}{l}0.002 \\
(0.003)\end{array}$ & 2.1 \\
\hline Log of total population (1993) & $\begin{array}{l}4.75 \\
(1.03)\end{array}$ & $\begin{array}{l}0.015 \\
(0.052)\end{array}$ & 0.3 \\
\hline Share of non-mestizo polulation (1993) & $\begin{array}{l}0.00 \\
(0.01)\end{array}$ & $\begin{array}{l}0.000 \\
(0.000)\end{array}$ & 6.6 \\
\hline Share of women (1993) & $\begin{array}{c}0.54 \\
(0.06)\end{array}$ & $\begin{array}{l}-0.003 \\
(0.004)\end{array}$ & -0.5 \\
\hline Block average elevation (meters) & $\begin{array}{c}1,606.78 \\
(114.54)\end{array}$ & $\begin{array}{l}-1.318 \\
(0.910)\end{array}$ & -0.1 \\
\hline Block average slope & $\begin{array}{l}89.95 \\
(0.72)\end{array}$ & $\begin{array}{l}-0.021 \\
(0.014)\end{array}$ & -0.0 \\
\hline Block present in 1948 & $\begin{array}{l}0.17 \\
(0.37)\end{array}$ & $\begin{array}{l}0.004 \\
(0.008)\end{array}$ & 2.2 \\
\hline Block present in 1970 & $\begin{array}{l}0.65 \\
(0.48)\end{array}$ & $\begin{array}{l}-0.005 \\
(0.027)\end{array}$ & -0.7 \\
\hline Block present in 1985 & $\begin{array}{l}0.85 \\
(0.36)\end{array}$ & $\begin{array}{c}-0.040^{* *} \\
(0.017)\end{array}$ & -4.8 \\
\hline Meters to schools & $\begin{array}{l}170.38 \\
(94.98)\end{array}$ & $\begin{array}{l}-4.907 \\
(4.524)\end{array}$ & -2.9 \\
\hline Meters to health centers & $\begin{array}{l}480.28 \\
(318.74)\end{array}$ & $\begin{array}{l}-1.109 \\
(7.880)\end{array}$ & -0.2 \\
\hline Meters to business centers & $\begin{array}{l}327.86 \\
(55.37)\end{array}$ & $\begin{array}{l}-1.997 \\
(3.009)\end{array}$ & -0.6 \\
\hline Block area $\left(\mathrm{m}^{2}\right)$ & $\begin{array}{l}4,989.12 \\
(7,237.34)\end{array}$ & $\begin{array}{r}-487.921 \\
(325.021)\end{array}$ & -9.6 \\
\hline
\end{tabular}

Notes: Column 1 reports summary statistics. Column 2 tests whether differences in paired blocks are correlated with state proximity using Equation 6 . Column 3 reports the magnitude of the estimate as a percentage of the sample mean. Each estimate in Column 2 comes from a separate regression of the covariate on the distance shock controlling for border fixed effects and each block's distance to a common fixed point on the border, clustering standard errors as described above. (Standard errors after bootstrapping are nearly identical to our main specification.) 
we will see) omitting them has little effect on treatment effect estimates. ${ }^{30}$

\subsection{Estimating average treatment effects}

To estimate local treatment effects, we run the following ordinary least squares regression:

$$
\Delta Y_{i j b}=\alpha_{b}+\beta \Delta d_{i j}+\theta \Delta X_{i j}+\lambda B_{i j}+\varepsilon_{i j b}
$$

As above, $\Delta Y_{i j b}$ is the difference in outcomes within block pairs and $\Delta X_{i j}$ is a vector of pair differences in the controls listed in Table $3 . B_{i j}$ is a vector of the distance from each block to a common fixed point on the border (akin to a distance running variable, to account for differences in distances to the border within a pair), and $\alpha_{b}$ is a vector of border fixed effects. ${ }^{31}$ We cluster standard errors at the level of the 42 border-pair clusters.

This approach follows Keele and Titiunik (2015) on geographic regression discontinuities, applied to a within-city setting with continuous shocks and variation in direction of treatment. Within a 300 meter bandwidth of the new border, it treats the distance shock as a random variable conditional on covariates and the distance running variables.

Predictions When the outcome variable, $\Delta Y_{i j}$, is the difference in current state service provision and legitimacy, we expect that $\beta_{\text {state }}>0$. That is, as blocks grow closer to the state, residents should report greater responsiveness in terms of policing and dispute management. As all blocks receive some degree of state services, this estimates the intensive margin of state presence. We are principally interested in the effects on combo governance, however, where the sign of $\beta_{\text {combo }}$ is ambiguous. A $\beta_{\text {combo }}>0$ would imply strategic complementarities with state rule.

Within-combo effects Note that we expect to estimate within-combo effects on gang rule. Combo borders generally do not coincide with comuna borders, and oftentimes the paired blocks will be under the same combo. For the most part, there was little to no combo governance until the 2000s, and so equation 6 estimates whether combo governance was more likely to emerge where the state is present or distant. In principle, however, this could imply a reallocation of combo effort within their territory, which in turn could imply interference

\footnotetext{
${ }^{30} \mathrm{~A}$ double-lasso method of choosing control variables chooses all variables, principally because of their predictive power for the dependent variable. None are selected for predicting the distance shock.

${ }^{31}$ Our main specification includes a fixed effect for each border and treatment direction-26 in all (2 for each of the 13 borders). These fixed effects account for the possibility of idiosyncratic variation arising from 13 new borders and the particular positions of stations. It also accounts for unobserved characteristics of the border, such as high drug value or other territorial characteristics that affect state or combo decision-making.
} 
between "treatment" and "control" blocks on either side of the new borders. In principle, this interference would be reduced by excluding from our estimation the block pairs that are closest to the border. We examine this as a robustness check, below. ${ }^{32}$

Other identification concerns We address other concerns, including measurement error and placebo tests, after examining results.

\subsection{Discerning mechanisms}

Combo strategic response Our criminal leader interviews and model implied that strategic complementarities with state rule should be strongest where gangs' rents from criminal activities other than extortion, such as drug retailing, are greatest. One way to test this is by interacting the treatment variable with a measure of the potential for illicit rents, $\pi_{i j}$ :

$$
\Delta Y_{i j b}=\alpha_{b}+\beta \Delta d_{i j}+\gamma \pi_{i j}+\delta \Delta d_{i j} \times \pi_{i j}+\theta \Delta X_{i j}+\lambda B_{i j}+\varepsilon_{i j b}
$$

If $\pi_{i j}$ is a standardized, normally-distributed measure, then the coefficient on $\Delta d_{i j}$ estimates the effect of growing closer to the state in neighborhoods with average levels of illicit rents (and so its magnitude should be similar to the average treatment effect estimated in equation $6)$. The coefficient on the interaction term estimates the responsiveness to illicit rents. If our criminal leader accounts are correct, we expect this to be positive.

Importantly, retail drug markets did not exist in any significant form in Medellín circa 1987. Drug sales and criminal governance both emerged in the 2000s. Arguably they coevolved, with gangs choosing to rule in the more profitable areas.

One option is to use proximity to drug markets as a measure of $\pi_{i j}$. In that case, equation 7 would assess the degree to which combo governance and the retail drug trade co-moved post-treatment. This would be consistent with the strategic response mechanism, but would not be a heterogeneity analysis based on exogenous characteristics.

To develop an exogenous proxy for future drug profitability, we use baseline data to predict the location of future drug markets. We first engaged two experts to map major drug markets - the city's principal organized crime journalist, and a former razón leader and mediator between gangs. They mapped the 139 major drug markets across the city, most of which developed in the 2000s. ${ }^{33}$ For each block pair, we calculated the average distance to

\footnotetext{
${ }^{32}$ Note that, because our unit of observation is the block pair, rather than threatening identification this possibility changes the interpretation of the treatment - as it affects both blocks rather than one street block in a consistent direction.

${ }^{33}$ We focus on major drug, permanent drug markets rather than smaller more mobile and largely unmapped minor drug corners.
} 
their 10 closest drug markets. This proximity varies widely. One block-pair includes a drug market, while the furthest is 1.5 kilometers away.

We then train a lasso model to predict a block pair's drug market proximity using repeated cross-validation. We use the full sample of all blocks in the 2019 city survey (not just those within a 300 meter bandwidth of the border). The pool of predictors include all baseline variables in Table 3 as well as the distance to neighborhoods in each income strata. We use a lasso model to facilitate interpretation of the predictors, but alternative methods produce similar results. ${ }^{34}$

Appendix Table A.2 reports lasso coefficients. Most baseline variables are selected by the model, with proximity to middle and high-income neighborhoods being among the strongest predictors. Figure A.3 shows that predicted proximity is strongly associated with actual post-treatment proximity. Appendix Figure A.4 shows that predicted values are correlated with other indicators of drug activity, such as the value of drug seizures 2014-19. To calculate $\pi_{i j}$, we average the predicted value for the block pair.

Economic development and sorting Over three decades, proximity to police, dispute resolution, and other local services could increase the volume of social and economic transactions. In addition, households and businesses who demand governance may move to bettergoverned neighborhoods. Both could increase demand for governance from both actors, as demonstrated in the model. We can test the influence of this mechanism by estimating average treatment effects on block pair differences in economic development on either side of the new borders. This is not an identification concern for $\beta$ when we look at treatment effects on gang governance, but rather a question of mechanism and interpretation - to what degree is $\beta$ attributable to the state's effects on growth versus the combo's strategic response. Note, however, that since most transactions are not directly mediated by either the gang or state, we would need to see a considerable rise in development or population for this mechanism to explain any rise in combo governance.

\footnotetext{
${ }^{34}$ We choose our specification by minimizing the prediction error via cross-validation, but the model selects most of the variables in each case. The predictions and the heterogeneity results are highly robust to including or excluding other categories of variables, including distances to the 1-10 closest police stations and municipal protection services.
} 
Table 4: Impacts on governance and legitimacy of being assigned to be 100 meters closer to the state, using historical headquarters

\begin{tabular}{|c|c|c|c|}
\hline \multirow{3}{*}{ Effect on $\Delta Y$} & & $\begin{array}{l}\text { Effect of moving } \\
100 \mathrm{~m} \text { closer to state }\end{array}$ & $\begin{array}{l}\text { Median change as } \\
\% \text { of sample mean }\end{array}$ \\
\hline & $\begin{array}{l}\text { Subsample } \\
\text { Mean } \\
\text { (SD) }\end{array}$ & $\begin{array}{l}\text { Estimate } \\
\quad(\mathrm{SE})\end{array}$ & Estimate \\
\hline & (1) & $(2)$ & $(3)$ \\
\hline \multicolumn{4}{|l|}{ Governance $(\mathrm{N}=570,563)$} \\
\hline$\Delta$ State Governance Index $(0-1)$ & $\begin{array}{l}0.41 \\
(0.19)\end{array}$ & $\begin{array}{c}0.012^{*} \\
(0.007)\end{array}$ & 11.6 \\
\hline$\Delta$ Combo Governance Index $(0-1)$ & $\begin{array}{l}0.32 \\
(0.22)\end{array}$ & $\begin{array}{c}0.020 * * * \\
(0.007)\end{array}$ & 24.9 \\
\hline \multicolumn{4}{|l|}{ Legitimacy $(\mathrm{N}=431,425)$} \\
\hline$\Delta$ State Legitimacy Index $(0-1)$ & $\begin{array}{l}0.58 \\
(0.14)\end{array}$ & $\begin{array}{c}0.001 \\
(0.008)\end{array}$ & 0.4 \\
\hline$\Delta$ Combo Legitimacy Index (0-1) & $\begin{array}{l}0.42 \\
(0.21)\end{array}$ & $\begin{array}{c}0.002 \\
(0.015)\end{array}$ & 2.2 \\
\hline Median $\Delta$ DistState (in $100 \mathrm{~m}$ ) & & 4.128 & \\
\hline
\end{tabular}

Notes: The unit of analysis is a pair of matched blocks on either side of a new border. The dependent variable is the difference in governance or legitimacy between the block pair. Each estimate in Column 2 comes from a regression of the dependent variable on the effect of growing 100 meters closer to the state (the distance shock), controlling for other baseline bock-pair differences, a running variable to the border, and border fixed effects. Standard errors are clustered at the level of 42 nearby block-pair clusters that share a treatment direction. Only residents (not business respondents) were asked about legitimacy, and some blocks have only residents, hence the lower sample size.

\section{$6 \quad$ Results}

\subsection{Governance}

We begin with perceived governance - the frequency with which survey respondents observed the state and combo responding to 17 forms of disorder or disputes in their neighborhoods.

Average treatment effects Table 4 reports the effect of a block growing 100 meters closer to the state. For every 100 meters closer to state headquarters, a block's reported level of state governance rises by $0.012(p=0.087)$. Recall that the median difference in distance is roughly 400 meters. Compared to the control mean of 0.41 , this implies the median change is associated with a $12 \%$ increase in citizen reports of state governance services (see Column $3)$.

Combo governance moves in the same direction as state governance, consistent with combo and state governance being strategic complements. For every 100 meters closer to 
Table 5: Heterogeneity: Impacts on governance and legitimacy of being 100 meters closer to the historical state, by predicted proximity to major drug plazas

\begin{tabular}{|c|c|c|c|c|c|}
\hline & \multirow{4}{*}{$\begin{array}{l}\text { Sample Mean } \\
\text { (SD) } \\
(1)\end{array}$} & \multicolumn{2}{|c|}{ Governance $(\Delta)$} & \multicolumn{2}{|c|}{ Legitimacy $(\Delta)$} \\
\hline & & State & Combo & State & Combo \\
\hline & & $\begin{array}{c}\text { Estimate } \\
\text { (SE) }\end{array}$ & $\begin{array}{c}\text { Estimate } \\
\text { (SE) }\end{array}$ & $\begin{array}{l}\text { Estimate } \\
\quad(\mathrm{SE})\end{array}$ & $\begin{array}{c}\text { Estimate } \\
\text { (SE) }\end{array}$ \\
\hline & & $(2)$ & $(3)$ & $(4)$ & $(5)$ \\
\hline Effect of moving $100 \mathrm{~m}$ closer to state & $\begin{array}{l}-4.971 \\
(4.368)\end{array}$ & $\begin{array}{l}0.011 \\
(0.007)\end{array}$ & $\begin{array}{c}0.017^{* *} \\
(0.008)\end{array}$ & $\begin{array}{c}0.001 \\
(0.007)\end{array}$ & $\begin{array}{c}0.000 \\
(0.016)\end{array}$ \\
\hline 100m closer to state X Predicted drug profitability (std.) & $\begin{array}{l}-1.899 \\
(5.240)\end{array}$ & $\begin{array}{l}0.004 \\
(0.003)\end{array}$ & $\begin{array}{c}0.009^{* * *} \\
(0.003)\end{array}$ & $\begin{array}{c}-0.007^{* *} \\
(0.003)\end{array}$ & $\begin{array}{c}-0.010^{* *} \\
(0.004)\end{array}$ \\
\hline Controls and fixed point running var & & $\checkmark$ & $\checkmark$ & $\checkmark$ & $\checkmark$ \\
\hline Bi-directional Border FE & & $\checkmark$ & $\checkmark$ & $\checkmark$ & $\checkmark$ \\
\hline$N$ & & 570 & 563 & 431 & 425 \\
\hline
\end{tabular}

Notes: This table estimates Equation 7, regressing governance and legitimacy outcomes on the distance shock, a standarized measure of predicted drug profitability, and an interaction between the two. Predicted profitability comes from the predicted values of a lasso regression of post-treatment drug market proximity on baseline variables and distance to wealthy neighborhoods. The coefficient on the distance shock estimates the treatment effect in neighborhoods at the average pair-average distance from drug plazas, and the coefficient on the interaction tells us how the impacts of the distance shock are different in neighborhoods closer to early drug corners.

state headquarters, combo governance rises by $0.020(p=0.001)$. At the median change in distance, this represents a $25 \%$ rise in gang governance services.

Note that combo governance was relatively rare in 1987. It emerged mainly in the $2000 \mathrm{~s}$ as retail drug markets developed. Therefore, in practical terms, these results are telling us that combos were more likely to develop governance service in areas closer to the state. Also, since most combo territories cross the new comuna borders, this implies that combos allocated attention to the portions of the territory with greater potential state presence.

Other survey outcomes tell a similar story, as illustrated in Appendix Table A.3. On blocks assigned to closer state headquarters, respondents reported that the state and combo were $9-16 \%$ easier to contact and about 13-20\% faster to respond (these are statistically significant for the combo only). As state distance grows closer, we see no changes in the proportion of people paying security fees, suggesting the market for protection was not the main reason gangs decided to rule. We do observe, however, that as state distance grows closer, respondents were $56 \%$ more likely to report that the combo's security fees are "too high." One interpretation is that combos target higher fees to a smaller number of locales where they also provide private goods, as some of our interviews suggest.

Evidence on combo strategic response to drug rents Combo governance appears to be highly responsive to state proximity. Table 5 estimates the heterogeneity analysis in Equation 7 using our proxy for predicted drug profitability, described in Section 5.5 above. 
Looking at state and combo governance, the coefficients on growing 100 meters closer to the state are similar to the estimates in Table 4 (as we expect given that the drug profitability measure is standardized to have zero mean and unit standard deviation.)

We are more interested in the coefficient on the interaction, which for combo governance is positive and statistically significant at the 1 percent level. The magnitude is about half that of the average effect of growing closer to the state. This implies that there is almost zero combo governance response on blocks two standard deviations further away from future drug markets, and a dramatic response on those two standard deviations closer to drug markets. ${ }^{35}$

In contrast, we do not see any evidence that state responsiveness is sensitive to drug market proximity.

State versus combo governance An obvious question is why did the distance shock have a larger and more precise effect on combo versus state governance? We should draw this conclusion with caution, for the two governance point estimates in Table 4 are not statistically distinguishable from one another. Nonetheless, there are several reasons to expect state and combo responses to differ.

One is that the state is not equally responsive to all forms of disturbance and disorder. Appendix Table A.4 looks at treatment effects on the 17 components of the governance index. In most cases, growing closer to the state increases reports of state responsiveness. Some of the exceptions are telling, however, such as children or drunks fighting on the street or domestic abuse. More minor street and household disorder has traditionally been the purview of informal authorities such as the combo. To the extent that the state does not tackle such incidents, it would attenuate the effect of any distance shock.

Another potentially more important factor is that the state has deliberately taken measures to mitigate the connection between distance and service provision. City agencies commonly require some degree of active outreach to peripheral communities. Also, police patrols are assigned to quadrants so that all areas of the comuna receive coverage.

The combo, meanwhile, is making a much more local allocation decision about where to allocate services and taxation within their territory. The results suggest that combos respond quite elastically to state proximity. ${ }^{36}$

\footnotetext{
${ }^{35}$ Note that results are virtually identical if we predict any number of nearest drug markets, from 1 to 20 , or if we expand the pool of baseline predictors to include closest proximity to state protection services. Finally, note that the measure of distance to drug markets is included in the regression, but we do not report it in the table as the coefficient is not relevant. The dependent variable is the difference in governance and legitimacy between the block pairs, and the distance from drug markets is by construction identical for the pair.

${ }^{36}$ This is consistent with an analysis of heterogeneous treatment effects by initial distance to the state. A 100 meter distance shock ought to be more consequential for block pairs that were initially closer to their state headquarters than those that were already far away to begin with - but only if the state had not
} 


\subsection{Legitimacy}

Table 4 also reports average treatment effects on state and combo legitimacy - a composite index of trust, perceived fairness, and satisfaction. Both estimates are close to zero. State and combo legitimacy do not rise as blocks get closer to the state. Rather, respondents simply report observing greater service provision from both the state and combo, and this does not affect their reported levels of trust in either actor or perceived fairness.

Table 5, however, illustrates striking variation in legitimacy according to distance from drug markets. When a block is relatively close to drug markets, increased state presence lowers state legitimacy. Combo legitimacy also suffers, despite higher levels of combo governance. In contrast, on blocks far away from drug markets, state presence produces greater state legitimacy, and the combo governance response produces combo legitimacy as well.

These effects can be quite large. Again, the average distance shock places one of the block pair about 400 meters closer to the state. On blocks one standard deviation closer to drug markets, state legitimacy falls by 0.032 ( $8 \%$ relative to the mean) and combo legitimacy falls by 0.04 ( $10 \%$ relative to the mean).

These results are consistent with our qualitative interviews in communities, where residents tended to emphasize their disdain for the presence of drug plazas. Retail narcotics sales bring undesirable people into the neighborhood, create local addicts, and can be a source of disorder, among other ills. There is suggestive evidence that the public grants the state and combo legitimacy when they govern but do not allow the sale of drugs in the immediate neighborhood.

The results also suggest that combo governance may in part be a strategy to minimize the loyalty and legitimacy penalty that comes from selling drugs. Recall that combo leaders gave two reasons for responding strategically to the state: providing order as a preventative measure, to reduce the likelihood that state representatives enter; and to bolster civilian loyalty. Conceivably the adverse legitimacy effect of state presence and drug proximity would be even worse if combos did not provide order and services

taken measures to distribute its services evenly. Appendix Table A.5 explores this for both state and combo governance. We create an indicator for block pairs above the median distance from their state headquarters in 1987, and we interact the distance shock with this term. The coefficient on the distance shock is the effect of the shock on block pairs initially close to their headquarters, and the coefficient on the interaction gives the differential impact of the distance shock between these near and far neighborhoods. The results suggest that blocks initially nearby the state do not experience a disproportionate change in state governance relative to those initially far from the state. The results are the opposite for the combo. The distance shock has a disproportionately larger effect on combo governance in the blocks initially closer to the state - again suggesting that the localized combo allocation decision is quite elastic to state proximity. 


\subsection{Economic development and sorting}

Finally, we consider whether the economic development mechanism contributes to the combo's governance response. Overall, the results suggest this is not a primary mechanism.

Table 6 estimates the effects of state proximity to the state on a range of economic and demographic measures from administrative data, the 2018 census, and our 2019 survey. To reduce the number of hypotheses tested, we construct standardized indexes of all measures, using principal components analysis for weights. We create separate indexes for administrative data (available for all blocks) and for our business questionnaire outcomes (since not all blocks had businesses to survey).

Neither index responds significantly to the distance shock. An index of survey outcomes from businesses actually has the opposite sign (although the magnitude is close to zero and not statistically significant). Thus there is no indication that small business size or profits change as the state grows closer. An index of all measures from administrative data suggests that development increases by 0.08 standard deviations for every 100 meters more distant from the state - about 0.3 standard deviations for the median change in distance. ${ }^{37}$ While in the expected direction, the magnitude is small and not statistically significant. Nor do we see any evidence of heterogeneous effects (Appendix Table A.6). In this specification, we do observe weak evidence that growing closer to the state increases economic development (among administrative outcomes only). But those impacts are concentrated in areas with low drug profitability - where combos govern the least. This implies combo governance isn't driven primarily (if at all) by general demand for governance.

Altogether, this is relatively weak evidence for the economic development and migration channel, especially because (as discussed in Section 4) the increase in transactions would likely have to be extremely large to: (i) overcome the crowding out that arises from normal duopolistic competition; and (ii) account for observable increases in combo governance.

\subsection{Robustness to alternative estimation strategies}

Generally, these results are robust to alternative estimation approaches. Appendix Table A.7 illustrates. Dropping controls have little effect on point estimates (consistent with the results of our balance tests), and the same is true of using fewer border fixed effects (one

\footnotetext{
${ }^{37}$ For some outcomes - housing value, in-migration, absence of firms, firm profits, firm sales, and firms' number of employees - the estimates point in the opposite direction of what we predict (though in all these cases the estimates are generally imprecise and small relative to the control mean). Other measures at least point in the expected direction - a poverty index, unemployment, population, land value, and total number of firms-but these estimates are likewise small compared to the control mean and some are imprecisely estimated. We see some statistically significant increases in human capital, measured by schooling rates and educational attainment. This could indicate a modest sorting effect.
} 


\section{Table 6: Impacts on neighborhood prosperity and demographics of being 100 meters closer}

to the local state

\begin{tabular}{|c|c|c|c|}
\hline \multirow{3}{*}{ Effect on $\Delta Y$} & & $\begin{array}{l}\text { Effect of moving } \\
100 \mathrm{~m} \text { closer to state }\end{array}$ & $\begin{array}{l}\text { Median change as } \\
\% \text { of sample mean }\end{array}$ \\
\hline & $\begin{array}{c}\text { Subsample } \\
\text { Mean } \\
\text { (SD) }\end{array}$ & $\begin{array}{l}\text { Estimate } \\
\quad(\mathrm{SE})\end{array}$ & \multirow{2}{*}{$\begin{array}{c}\text { Estimate } \\
\text { (3) }\end{array}$} \\
\hline & (1) & $(2)$ & \\
\hline Administrative outcomes $(\mathrm{N}=475)$, index & $\begin{array}{c}0.00 \\
(1.00)\end{array}$ & $\begin{array}{c}0.076 \\
(0.050)\end{array}$ & \\
\hline Multidimentional Poverty Index (2018) & $\begin{array}{l}13.62 \\
(14.22)\end{array}$ & $\begin{array}{l}-0.309 \\
(0.613)\end{array}$ & -9.4 \\
\hline Unemployment rate (2018) & $\begin{array}{l}0.11 \\
(0.07)\end{array}$ & $\begin{array}{l}-0.003 \\
(0.004)\end{array}$ & -12.6 \\
\hline Schooling rate $(2018)$ & $\begin{array}{l}0.90 \\
(0.12)\end{array}$ & $\begin{array}{c}0.011^{* *} \\
(0.005)\end{array}$ & 5.0 \\
\hline Log of total population (2018) & $\begin{array}{l}5.56 \\
(1.36)\end{array}$ & $\begin{array}{c}0.002 \\
(0.083)\end{array}$ & 0.1 \\
\hline Log of economic value of land (2014) & $\begin{array}{l}13.34 \\
(0.63)\end{array}$ & $\begin{array}{c}0.018 \\
(0.014)\end{array}$ & 0.6 \\
\hline Log of average housing value & $\begin{array}{l}11.85 \\
(0.62)\end{array}$ & $\begin{array}{l}-0.005 \\
(0.031)\end{array}$ & -0.2 \\
\hline Share with no ed. completed (2018) & $\begin{array}{l}2.00 \\
(1.77)\end{array}$ & $\begin{array}{c}-0.129 * \\
(0.069)\end{array}$ & -27.2 \\
\hline Share completed primary ed. (2018) & $\begin{array}{l}79.91 \\
(7.48)\end{array}$ & $\begin{array}{c}0.827^{* *} \\
(0.377)\end{array}$ & 4.3 \\
\hline Share completed secondary ed. (2018) & $\begin{array}{l}63.57 \\
(12.32)\end{array}$ & $\begin{array}{c}0.986^{*} \\
(0.518)\end{array}$ & 6.4 \\
\hline Share completed higher ed. (2018) & $\begin{array}{l}24.83 \\
(15.45)\end{array}$ & $\begin{array}{c}0.598 \\
(0.511)\end{array}$ & 9.9 \\
\hline Percent of population aged 0 to 14 (2018) & $\begin{array}{l}15.94 \\
(6.07)\end{array}$ & $\begin{array}{l}-0.275 \\
(0.302)\end{array}$ & -7.1 \\
\hline Percent of population who recently migrated (2018) & $\begin{array}{l}4.39 \\
(3.72)\end{array}$ & $\begin{array}{l}-0.008 \\
(0.174)\end{array}$ & -0.8 \\
\hline Survey outcomes $(\mathrm{N}=231)$, index & $\begin{array}{c}0.00 \\
(1.00)\end{array}$ & $\begin{array}{l}-0.033 \\
(0.045)\end{array}$ & \\
\hline Absence of firms & $\begin{array}{c}0.24 \\
(0.43)\end{array}$ & $\begin{array}{c}0.012 \\
(0.016)\end{array}$ & 20.2 \\
\hline Log of total number of firms & $\begin{array}{l}1.50 \\
(1.17)\end{array}$ & $\begin{array}{l}0.018 \\
(0.040)\end{array}$ & 4.9 \\
\hline Log of mean profits (2019) & $\begin{array}{l}13.36 \\
(1.16)\end{array}$ & $\begin{array}{l}-0.022 \\
(0.074)\end{array}$ & -0.7 \\
\hline Log of mean sales (2019) & $\begin{array}{l}14.78 \\
(1.17)\end{array}$ & $\begin{array}{l}-0.032 \\
(0.087)\end{array}$ & -0.9 \\
\hline Number of employees (2019) & $\begin{array}{l}2.38 \\
(2.70)\end{array}$ & $\begin{array}{l}-0.128 \\
(0.254)\end{array}$ & -22.8 \\
\hline Number of observations & & 570 & \\
\hline Minimum N & & 228 & \\
\hline
\end{tabular}

Notes: Each estimate comes from a separate regression. The indexes are standardized to have zero mean and unit standard deviation. They are weighted averages of the components measures below, where weights come from a principal components analysis. Business survey data are not available for all blocks (since some blocks do not have businesses) and so we compute a separate index for these measures. 
per border). Removing clustering of standard errors increases precision, as expected. We see similar results if we match blocks to the closest block across any border (rather than the closest block across the closest border), and if we use a 200 meter bandwidth instead of 300 meters along borders. Finally, one might worry that, on blocks closest to the border, survey data are contaminated by circumstances on the other side of the border - a potential violation of the independence assumption. Dropping the $25 \%$ of blocks closest to the order does not diminish our results.

\subsection{Sensitivity to potential identification threats}

Potential for other unobserved confounders Are there other unobserved block characteristics that are associated both with differences in proximity to historical state presence and to motives for combo governance? Our border discontinuity should reduce the likelihood of these confounders. In addition, they would need to have a stronger relationship with both combo and state governance than our observed confounders (such as the availability of other state services, or the distance to business agglomerations). This is possible. For example, some borders might not have been arbitrarily drawn - although our anecdotal evidence on the process suggests otherwise. We address this by conducting a placebo exercise. We randomly matched 1,500 times our baseline sample of blocks located within 300 meters of comuna borders with other blocks inside the same comuna, ensuring that the matched blocks are at most 600 meters away from each other - so that we resemble our baseline specification. To build our treatment variable, we assign one of the block pairs to state services within the comuna and the other to services in the neighboring comuna (depending on the distance to average services for each). The distribution of treatment effects for combo governance and legitimacy is reported in Figure A.5. Our observed treatment effects lie at the edge of the distribution, suggesting they are unlikely to be explained by other confounders.

Measurement error correlated with treatment Finally, we consider different kinds of measurement error correlated with treatment, and judge that these are unlikely to account for the large crowding in effects we observe.

First, few forms of measurement error will bias our estimate on combo governance upwards. For instance, if people tend to understate gang rule in general, we will tend to underestimate crowding in. We show this in Appendix C. In only one scenario will we overestimate crowding in: if citizens under-report gang governance when gang governance is high and the state is far away, but do not misreport when the government is close.

Second, the correlates of combo governance reported in Appendix Table A.1 suggest that people are comfortable talking about combos. In particular, we see a positive correlation 
between combo density and governance, and negative correlations between distance from gang and razón central locations and combo governance. This accords with our qualitative experience: when interviewed privately, people spoke freely about combo rule.

Third, we tested this using a survey experiment. We took one of the variables we thought could be the most sensitive - whether people paid "taxes" to the combo in the form of security fee and extortion payments. In our city-wide survey of thousands of residents, we randomly assigned respondents to either a direct question on whether they paid the combo, versus a randomized-response technique, where they privately flipped a coin and responded to the question honestly or not depending on the flip. In other contexts, this method has detected under-reporting of sensitive behaviors. ${ }^{38}$ With the whole sample, randomized response $(\mathrm{RR})$ elicited an extortion rate of $22.6 \%$ from businesses and $6 \%$ from households, compared to $19.4 \%$ and $7.8 \%$ with directly responses (DR). The differences RR-DR run in opposite directions for households and businesses, and are not statistically significant.

Appendix Figure C.1 plots this block averages for this RR-DR difference on block combo governance in the full city sample, and finds little systematic correlation. Appendix Table C.1 reports summary statistics within our sample of blocks close to new borders, and examines correlates between differential reporting and our treatment variable. On average, the direct responses on vacunas are 6 percentage points lower than the randomized response (RR), as seen in Column 1 (first row). So there is evidence of slight under-reporting in this subsample, even if it is not statistically significant. There is no statistically significant correlation, however, between the RR-DR pair-block difference and difference in distance to state headquarters. As the state grows closer, direct reporting decreases somewhat relative to randomized response. But this is small and imprecise. Furthermore, if under-reporting is larger as the state grows closer, it is likely that our main estimates are a lower bound of the actual treatment effect (i.e., our results would be understating the strategic complementarities).

We also investigate whether patterns of non-response are correlated with treatment. For instance, people might decide to skip combo governance questions if they are uncomfortable. As we show in Table C.1 (rows 2 and 3), respondents answered about 85\% of combo governance and legitimacy questions, compared to $90 \%$ for the state, again consistent with slight under-reporting of combo governance (which, as we noted, would act to understate crowding in). People are somewhat less likely to answer these questions the closer they are to the state, however - the opposite of the direction we are worried about. If the proportion of questions indeed proxy for under-reporting, this pattern again implies our findings are

\footnotetext{
${ }^{38}$ Others were asked the same question using a List Experiment, where half are asked to give the number of four nonsensitive actions they engaged in, and half see a list of five actions including paying extortion. In general, these list experiments are extremely noisy. Yet, the results are consistent with what we see in these randomized response and direct response questions. There is no evidence of systematic measurement error.
} 
more likely a lower bound of the actual treatment effect.

\section{Conclusions}

Thousands of major city governments operate in an uneasy duopoly of coercion, rule, and taxation with urban gangs. Many such governments, like Medellín's, are strong, in the sense that they levy taxes and provide extensive public and private goods. Many have even deliberately attempted to expand state capacity in slums and low-income neighborhoods. Yet organized crime and gang rule over civilians have proven enduring.

Our work suggests a few important insights. First, at least in Medellín's low- and middleincome neighborhoods, the market for protection was not the main reason gangs decided to rule. Rather, this was overshadowed by indirect motives to govern, ones that arose from other business lines, especially retail drug sales. What's more, citizens tend to respond the state and gang with trust and satisfaction, so long as that the public goods are not bundled with public bads like drug sales. It seems that criminal groups govern not only to keep the police from having to enter profitable neighborhoods, but also to make up for the legitimacy they and citizen collaboration they lose from selling drugs.

The presence or absence of this indirect motive may help explain patterns of gang rule in other cities. Rio de Janeiro, for instance, has extensive retail drug markets and also expansive, militarized gang rule with little or no taxation of residents. San Salvador, on the other hand, has limited local drug markets and much more extractive gangs. Our theory and empirical analysis predicts that, ceteris paribus, efforts to expand state capacity would be more likely to lead to crowding in in Rio de Janeiro and crowding out in San Salvador.

Second, both our results and our theoretical discussion suggest that common policy interventions could backfire in the presence of these indirect motives to rule. For instance, popular responses to organized crime and extortion include police crackdowns, ease of anonymous denunciation, or facilitating collective action among merchants. Crackdowns and denunciations could actually increase incentives for the gang to govern and foster legitimacy, especially in the most valuable neighborhoods. And efforts to reduce extortion overlook the fact that many gangs would have an incentive to rule even if they were unable to collect fees at all. And since extortion is a modest percentage of business sales, merchants may have weak incentives to undertake costly, risky collective action, especially if they are receiving real protection in return.

Third, the fact that high-income barrios in Medellín do not have combos or criminal governance suggests that on some margin gang and state rule may be substitutes. The main focus of this study is understanding variation within low- and middle-income neighborhoods, 
of course, and this is an important scope condition of our results. But a reasonable hypothesis is that the state's desire for control and legitimacy in high-earning areas leads it to maintain a large state presence, and this may contribute to the crowding out of gangs and gang rule.

Fourth, our results also point to a terrible policy trade-off for city governments: weakening gangs could make their neighborhoods more violent and coercive. This comes from our observation that gang abuses, including purely extractive extortion, are disciplined by the gang's need to protect drug rents by fostering community loyalty, collaboration, and respect. If cities legalized drug sales, treated addicts, or otherwise reduced retail demand for drugs, gangs would have fewer incentives to treat residents well, and maintain peace in their neighborhoods. Similarly, suppose a government or non-profit tried to de-legitimize gangs among residents and incentivize denouncement to authorities through social norms marketing campaigns or collective action. Even if effective, by eliminating the gang's incentives to win residents' loyalty this could inadvertently lead to more abusive and extortionate patterns of rule. In short, curbing criminal governance, which after all brings order to a significant share of the population, can have major unintended consequences, ones which city governments do not appear to be aware of.

\section{References}

Acemoglu, D., A. Cheema, A. I. Khwaja, and J. A. Robinson (2020). Trust in State and Nonstate Actors: Evidence from Dispute Resolution in Pakistan. Journal of Political Economy 128(8), 3090-3147.

Arias, E. D. (2006). The Dynamics of Criminal Governance: Networks and Social Order in Rio de Janeiro. Journal of Latin American Studies 38(2), 293-325.

Arjona, A. (2016). Rebelocracy. Cambridge University Press.

Berman, E., J. H. Felter, J. N. Shapiro, and E. Troland (2013). Modest, Secure, and Informed: Successful Development in Conflict Zones. American Economic Review 103(3), $512-17$.

Berman, E. and A. M. Matanock (2015). The Empiricists' Insurgency. Annual Review of Political Science 18, 443-464.

Berman, E., J. N. Shapiro, and J. H. Felter (2011). Can Hearts and Minds be Bought? The Economics of Counterinsurgency in Iraq. Journal of Political Economy 119(4), 766-819.

Blattman, C., G. Duncan, B. Lessing, F. Martinez, and S. Tobon (2023). Pax Criminalis. Working paper.

Blattman, C., G. Duncan, B. Lessing, and S. Tobon (2023). State-building on the Margin: Lessons from an Urban Experiment in Medellín. Working paper. 
Cammett, M. and L. M. MacLean (2014). The Politics of Non-State Social Welfare. Cornell University Press.

Crost, B., J. H. Felter, and P. B. Johnston (2016). Conditional Cash Transfers, Civil Conflict and Insurgent Influence: Experimental Evidence from the Philippines. Journal of Development Economics 118, 171-182.

Dell, M. (2015). Trafficking Networks and the Mexican Drug War. American Economic Review 105(6), 1738-79.

Gambetta, D. (1996). The Sicilian Mafia: the Business of Private Protection. Harvard University Press.

Grossman, H. I. (1996). Rival Kleptocrats: the Mafia Versus the State, pp. 143-155. Cambridge University Press.

Henn, S. J. (2022). Complements or substitutes? how institutional arrangements bind chiefs and the state in africa. American Political Science Review.

Keele, L. J. and R. Titiunik (2015). Geographic Boundaries as Regression Discontinuities. Political Analysis 23(1), 127-155.

Konrad, K. A. and S. Skaperdas (2012). The Market for Protection and the Origin of the State. Economic Theory 50(2), 417-443.

Leeson, P. T. (2007). An-arrgh-chy: The Law and Economics of Pirate Organization. Journal of Political Economy 115(6), 1049-1094.

Lessing, B. (2020). Conceptualizing Criminal Governance. Perspectives on Politics, 1-20.

Lessing, B., D. Block, and E. Stecher (2019). Criminal Governance in Latin America: an Empirical Approximation. Working paper.

Lessing, B. and G. Denyer Willis (2019). Legitimacy in criminal governance: Managing a drug empire from behind bars. American Political Science Review 113(2), 584-606.

Levitt, S. D. and S. A. Venkatesh (2000). An Economic Analysis of a Drug-Selling Gang's Finances. The Quarterly Journal of Economics 115(3), 755-789.

Magaloni, B., E. Franco-Vivanco, and V. Melo (2020). Killing in the Slums: Social Order, Criminal Governance, and Police Violence in Rio de Janeiro. American Political Science Review 114(2), 552-572.

Martin, G. (2012). Medellín Tragedia y Resurrección: Mafia, Ciudad y Estado, 1975-2012. Planeta.

McGuire, M. C. and M. Olson (1996). The Economics of Autocracy and Majority Rule: the Invisible Hand and the Use of Force. Journal of Economic Literature 34(1), 72-96.

Melnikov, N., C. Schmidt-Padilla, and M. M. Sviatschi (2021). Gangs, labor mobility, and development. Working Paper.

North, D. C., J. J. Wallis, and B. R. Weingast (2009). Violence and Social Orders: A 
Conceptual Framework for Interpreting Recorded Human History. Cambridge University Press.

Olson, M. (1993). Dictatorship, Democracy, and Development. American Political Science Review 87(3), 567-576.

Reuter, P. (1983). Disorganized Crime: Illegal Markets and the Mafia. MIT Press.

Salazar, A. and A. M. Jaramillo (1996). Medellín: Las subculturas del narcotráfico. Cinep.

Sánchez De La Sierra, R. (2020). On the Origins of the State: Stationary Bandits and Taxation in Eastern Congo. Journal of Political Economy 128(1), 000-000.

Sánchez De la Sierra, R., K. Titeca, H. S. Xie, A. J. Malukisa, and A. A. Lameke (2022). The real state: Inside the congo's traffic police agency. Working Paper.

Skaperdas, S. (2001). The Political Economy of Organized Crime: Providing Protection When the State Does Not. Economics of Governance 2(3), 173-202.

Skaperdas, S. and C. Syropoulos (1996). Gangs as Primitive States, pp. 61-81. Cambridge University Press.

Skarbek, D. (2011). Governance and Prison Gangs. American Political Science Review 105(4), 702-716.

Skarbek, D. (2014). The Social Order of the Underworld: How Prison Gangs Govern the American Penal System. Oxford University Press.

Thoumi, F. (2017). Medellín: ¿Comunas sin cohesión social?, pp. 139-174. Universidad EAFIT.

Tilly, C. (1985). War Making and State Making as Organized Crime. Violence: A reader, $35-60$. 


\section{Appendix}

\section{A Supplemental tables and figures}

Figure A.1: Combo governance by barrio, 2019

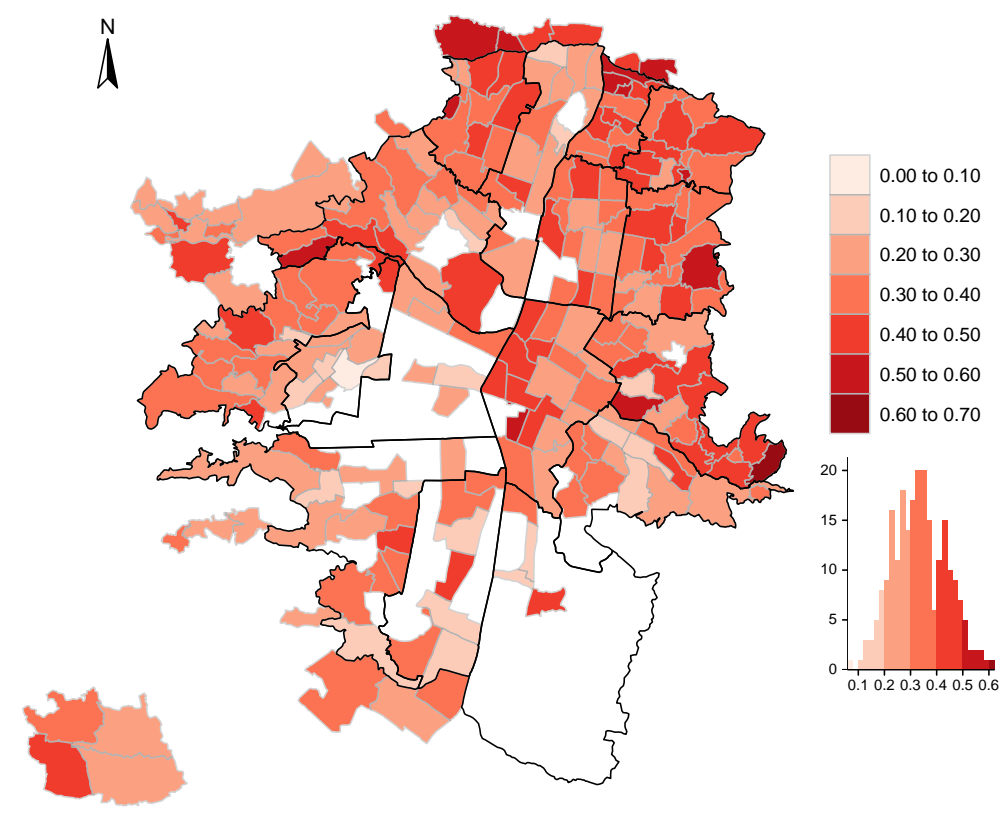

Notes: Each barrio's value represents the average combo governance reported for all 17 items from Table 2. Combo governance is an index running from 0 (never responds) to 1 (always responds). We did not survey high-income barrios. 
Table A.1: Correlates of combo governance

\begin{tabular}{|c|c|c|c|c|c|c|c|c|c|c|c|c|}
\hline & \multirow[b]{2}{*}{$\begin{array}{c}\text { Sample Mean } \\
\text { (SD) } \\
(1) \\
\end{array}$} & \multicolumn{11}{|c|}{ Combo Governance } \\
\hline & & $\begin{array}{c}\text { Estimate } \\
\text { (SE) } \\
\text { [p-value] } \\
(2)\end{array}$ & $\begin{array}{c}\text { Estimate } \\
\text { (SE) } \\
\text { [p-value] } \\
(3)\end{array}$ & $\begin{array}{c}\text { Estimate } \\
\text { (SE) } \\
\text { [p-value] } \\
(4)\end{array}$ & $\begin{array}{c}\text { Estimate } \\
\text { (SE) } \\
\text { [p-value] } \\
(5)\end{array}$ & $\begin{array}{c}\text { Estimate } \\
\text { (SE) } \\
\text { [p-value] } \\
\quad(6)\end{array}$ & $\begin{array}{c}\text { Estimate } \\
\text { (SE) } \\
\text { [p-value] } \\
(7)\end{array}$ & $\begin{array}{c}\text { Estimate } \\
\text { (SE) } \\
\text { [p-value] } \\
(8)\end{array}$ & $\begin{array}{c}\text { Estimate } \\
\text { (SE) } \\
\text { [p-value] } \\
\quad(9)\end{array}$ & $\begin{array}{c}\text { Estimate } \\
\text { (SE) } \\
\text { [p-value] } \\
(10)\end{array}$ & $\begin{array}{c}\text { Estimate } \\
\text { (SE) } \\
\text { [p-value] } \\
(11)\end{array}$ & $\begin{array}{c}\text { Estimate } \\
\text { (SE) } \\
\text { [p-value] } \\
(12)\end{array}$ \\
\hline Log of drug seizure value & $\begin{array}{l}18.135 \\
(1.433)\end{array}$ & $\begin{array}{c}0.059^{* * *} \\
(0.022) \\
{[0.008]}\end{array}$ & & & & & & & & & & \\
\hline Avg distance to drug corners & $\begin{array}{l}686.075 \\
(417.486)\end{array}$ & & $\begin{array}{l}0.027 \\
(0.022) \\
{[0.226]}\end{array}$ & & & & & & & & & \\
\hline Distance to large drug corner & $\begin{array}{l}1,616.102 \\
(1,028.670)\end{array}$ & & & $\begin{array}{l}0.024 \\
(0.022) \\
{[0.277]}\end{array}$ & & & & & & & & \\
\hline Distance from gang HQ & $\begin{array}{l}2.543 \\
(2.059)\end{array}$ & & & & $\begin{array}{c}-0.153^{* * *} \\
(0.022) \\
{[0.000]}\end{array}$ & & & & & & & \\
\hline Count of combo groups & $\begin{array}{c}0.351 \\
(0.563)\end{array}$ & & & & & $\begin{array}{c}0.093^{* * *} \\
(0.022) \\
{[0.000]}\end{array}$ & & & & & & \\
\hline Distance to razón HQ & $\begin{array}{l}14.928 \\
(9.648)\end{array}$ & & & & & & $\begin{array}{c}-0.118^{* * *} \\
(0.025) \\
{[0.000]}\end{array}$ & & & & & \\
\hline Meters to clinics and schools & $\begin{array}{l}368.474 \\
(173.523)\end{array}$ & & & & & & & $\begin{array}{c}-0.066^{* * *} \\
(0.022) \\
{[0.003]}\end{array}$ & & & & \\
\hline Meters to business center & $\begin{array}{c}328.843 \\
(61.826)\end{array}$ & & & & & & & & $\begin{array}{l}-0.027 \\
(0.022) \\
{[0.232]}\end{array}$ & & & \\
\hline Block average elevation & $\begin{array}{c}1,613.698 \\
(132.844)\end{array}$ & & & & & & & & & $\begin{array}{c}0.119^{* * *} \\
(0.022) \\
{[0.000]}\end{array}$ & & \\
\hline Poverty Index (2018) & $\begin{array}{l}14.413 \\
(15.641)\end{array}$ & & & & & & & & & & $\begin{array}{c}0.151^{* * *} \\
(0.022) \\
{[0.000]}\end{array}$ & \\
\hline Distance to state & $\begin{array}{c}1,319.409 \\
(937.994)\end{array}$ & & & & & & & & & & & $\begin{array}{l}0.009 \\
(0.022) \\
{[0.697]}\end{array}$ \\
\hline$N$ & & 2,014 & 2,014 & 2,014 & 1,996 & 2,014 & 1,499 & 2,014 & 1,994 & 2,014 & 2,014 & 2,004 \\
\hline
\end{tabular}


Figure A.2: Relationship between combo legitimacy and state legitimacy, 2019

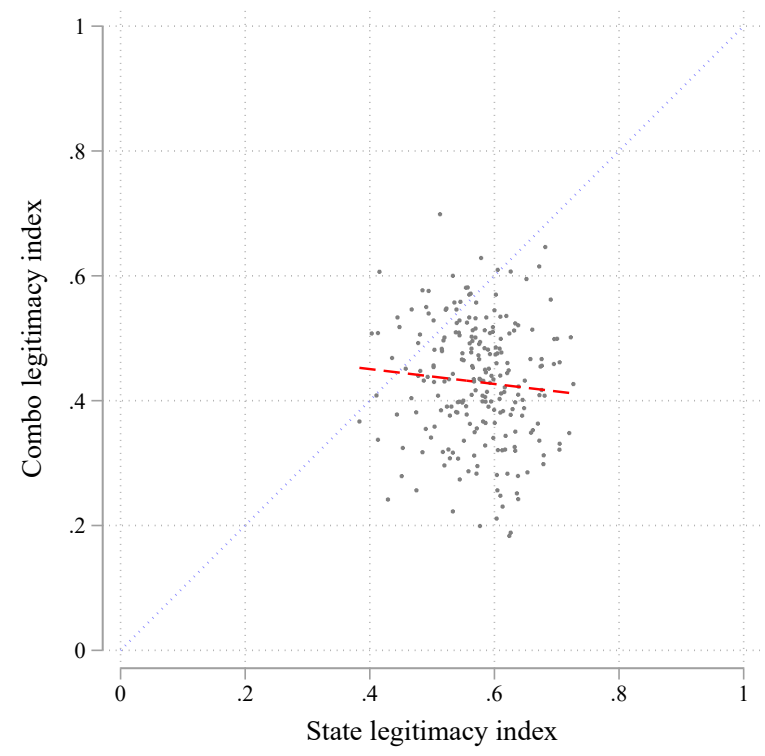

Notes: Each dot is a barrio average, and the dashed line indicates fitted values (correlation is -0.08).

We did not survey high-income barrios.

Figure A.3: Relationship between distance to drug corners and its predicted value

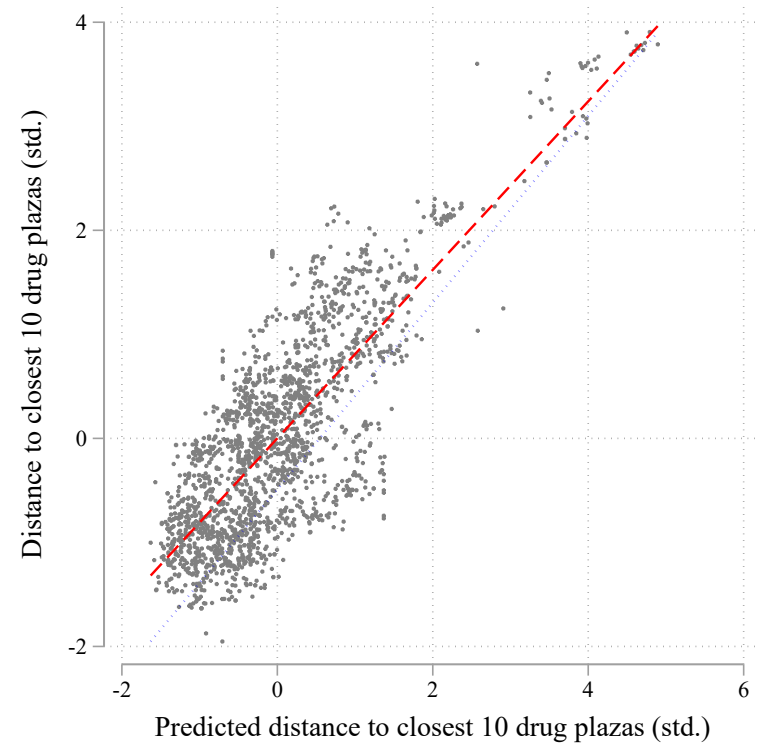

Notes: The sample includes all blocks in the 2019 city survey, including those more than 300 meters from a new border. We plot average distance to the 10 nearest major drug corners (the vertical axis) against predicted values from the lasso regression reported in Appendix Table A.2. Each dot is a block, and the dashed line indicates fitted values (correlation = 0.81). 
Table A.2: Baseline predictors of proximity to drug markets

\begin{tabular}{lc}
\hline Standarized index & Lasso Coefficients \\
\hline Total women (1993) & -0.090 \\
Median age (1993) & -0.046 \\
Total population no education (1993) & 0.030 \\
Share of population with primary education (1993) & -0.108 \\
Share of population with secondary education (1993) & -0.021 \\
Share of population with higher educ. (1993) & 0.007 \\
Log of total population (1993) & -0.033 \\
Total non-mestizo polulation (1993) & -0.003 \\
Share of women (1993) & 0.069 \\
Share of non-mestizo polulation (1993) & -0.021 \\
Share of population no education (1993) & -0.066 \\
Median number of room (1993) & 0.019 \\
Distance to neighborhood of income level 1 & -0.019 \\
Distance to neighborhood of income level 2 & -0.175 \\
Distance to neighborhood of income level 3 & 0.435 \\
Distance to neighborhood of income level 4 & 1.106 \\
Distance to neighborhood of income level 5 & 2.846 \\
Distance to neighborhood of income level 6 & -0.003 \\
Distance to neighborhood of income level 4, 5 or 6 & -1.082 \\
Distance to neighborhood of income level 5 or 6 & -3.100 \\
Distance to education centers (mean in comuna) & -0.124 \\
Distance to local business centers (mean in comuna) & -0.019 \\
Distance to transport (subway stations) & 0.032 \\
Meters to health centers & 0.248 \\
Meters to schools & 0.096 \\
Constant & 0.004 \\
\hline
\end{tabular}

Notes: The sample includes all blocks in the 2019 city survey, including those more than 300 meters from a new border. The dependent variable is a block's average distance to the 10 nearest drug corners in the mid-2000s. We estimate a lasso regression using all baseline variables in Table 3 as well as the distance to neighborhoods in each income strata. For cross validation, we employed a 10-fold approach. This means that a random tenth of the sample was left aside to test the model trained on the rest of the data. This process allows us to compute a crossvalidation error per each fold, which is then averaged to obtain a cross-validation error measure for the model. 
Figure A.4: Relationship between predicted distance to drug corners and drug seizures

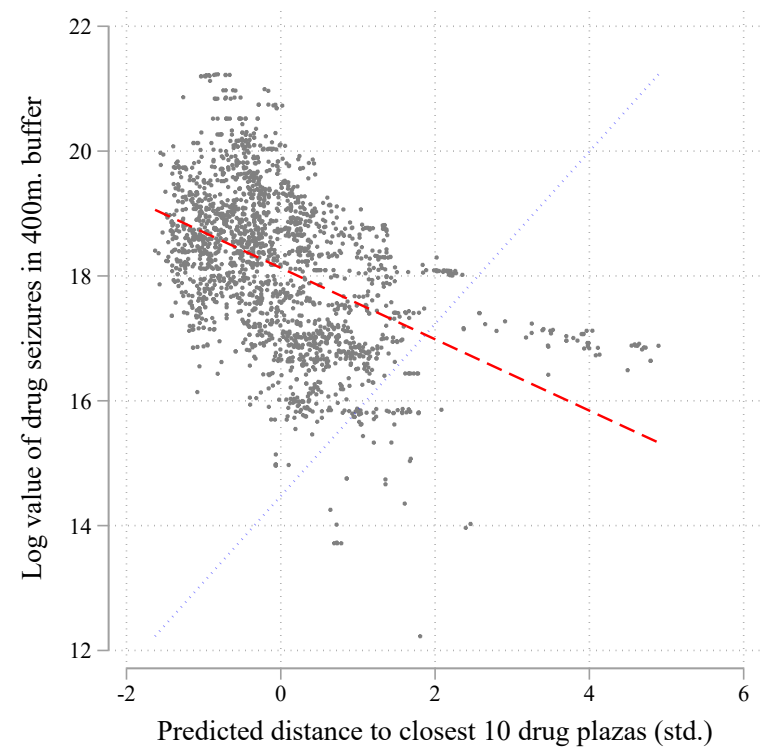

Notes: The sample includes all blocks in the 2019 city survey, including those more than 300 meters from a new border. We plot the logged value of all drug seizures from 2014-19 in a 400 meter radius of each block (the vertical axis) against predicted values of drug market proximity from the lasso regression reported in Appendix Table A.2. Each dot is a block, and the dashed line indicates fitted values (correlation $=-0.53$ ). 
Table A.3: Impacts on other governance outcomes of being assigned to be $100 \mathrm{~m}$ closer to the state, using historical headquarters

\begin{tabular}{|c|c|c|c|}
\hline \multirow{3}{*}{ Effect on $\Delta Y$} & & $\begin{array}{l}\text { Effect of moving } \\
100 \mathrm{~m} \text { closer to state }\end{array}$ & $\begin{array}{l}\text { Median change as } \\
\% \text { of sample mean }\end{array}$ \\
\hline & $\begin{array}{c}\text { Subsample } \\
\text { Mean } \\
\text { (SD) }\end{array}$ & $\begin{array}{l}\text { Estimate } \\
\quad(\mathrm{SE})\end{array}$ & Estimate \\
\hline & (1) & $(2)$ & $(3)$ \\
\hline \multicolumn{4}{|l|}{ Panel A: Effects on state efficacy } \\
\hline How easy is it to contact the state & $\begin{array}{c}0.46 \\
(0.18)\end{array}$ & $\begin{array}{l}0.010 \\
(0.008)\end{array}$ & 9.3 \\
\hline How fast is the state & $\begin{array}{l}0.39 \\
(0.21)\end{array}$ & $\begin{array}{c}0.012 \\
(0.008)\end{array}$ & 13.2 \\
\hline \multicolumn{4}{|l|}{ Panel B: Effects on combo efficacy } \\
\hline How easy is it to contact the combo & $\begin{array}{c}0.56 \\
(0.26)\end{array}$ & $\begin{array}{c}0.021^{* *} \\
(0.009)\end{array}$ & 15.8 \\
\hline How fast is the combo & $\begin{array}{l}0.52 \\
(0.30)\end{array}$ & $\begin{array}{l}0.025^{*} \\
(0.015)\end{array}$ & 20.2 \\
\hline \multicolumn{4}{|l|}{ Panel C: Effects on payments to state } \\
\hline Percentage of bussines paying taxes & $\begin{array}{c}0.52 \\
(0.49)\end{array}$ & $\begin{array}{l}0.009 \\
(0.023)\end{array}$ & 6.9 \\
\hline Approves of city's local taxes & $\begin{array}{c}0.60 \\
(0.33)\end{array}$ & $\begin{array}{r}-0.008 \\
(0.020)\end{array}$ & -5.8 \\
\hline Says local taxes are too high & $\begin{array}{l}0.61 \\
(0.34)\end{array}$ & $\begin{array}{l}-0.001 \\
(0.016)\end{array}$ & -1.0 \\
\hline \multicolumn{4}{|l|}{ Panel D: Effects on payments to combo } \\
\hline Payment rate of security fee & $\begin{array}{c}0.12 \\
(0.27)\end{array}$ & $\begin{array}{l}0.006 \\
(0.010)\end{array}$ & 19.9 \\
\hline Says neighbors pay security fees & $\begin{array}{l}0.33 \\
(0.37)\end{array}$ & $\begin{array}{l}-0.003 \\
(0.014)\end{array}$ & -3.5 \\
\hline Approves of combo security fee & $\begin{array}{c}0.06 \\
(0.16)\end{array}$ & $\begin{array}{l}-0.004 \\
(0.006)\end{array}$ & -25.3 \\
\hline Says security fees are too high & $\begin{array}{c}0.28 \\
(0.37)\end{array}$ & $\begin{array}{c}0.038^{* *} \\
(0.015)\end{array}$ & 56.4 \\
\hline $\begin{array}{l}\text { Number of observations } \\
\text { Minimum N }\end{array}$ & & $\begin{array}{l}573 \\
332\end{array}$ & \\
\hline
\end{tabular}

Notes: The unit of analysis is a pair of matched blocks on either side of a new border. The dependent variable is the difference in survey outcomes between the block pair. Each estimate in Column 2 comes from a regression of the dependent variable on the distance shock, controlling for other baseline bock-pair differences, a running variable to the border, and border fixed effects. Standard errors are clustered at the level of 42 nearby block-pair clusters that share a treatment direction. Only residents (not business respondents) were asked about legitimacy, and some blocks have only residents, hence the lower sample size.. 
Table A.4: Coefficient of closeness to state services for blocks along the inner comuna borders of Medellín on governance index components

\begin{tabular}{|c|c|c|c|}
\hline \multirow{3}{*}{ Effect on $\Delta Y$} & \multicolumn{2}{|r|}{ State } & \multirow{2}{*}{$\begin{array}{l}\text { Combo } \\
\text { Estimate } \\
\text { (SE) }\end{array}$} \\
\hline & $\begin{array}{c}\text { Subsample } \\
\text { Mean } \\
\text { (SD) }\end{array}$ & $\begin{array}{c}\text { Estimate } \\
\text { (SE) }\end{array}$ & \\
\hline & (1) & $(2)$ & $(3)$ \\
\hline Governance Index & $\begin{array}{l}0.08 \\
(0.25)\end{array}$ & $\begin{array}{l}0.012^{*} \\
(0.007)\end{array}$ & $\begin{array}{c}0.020^{* * *} \\
(0.007)\end{array}$ \\
\hline HH: Someone refuses to pay a big debt & $\begin{array}{l}-0.15 \\
(0.32)\end{array}$ & $\begin{array}{l}0.011 \\
(0.013)\end{array}$ & $\begin{array}{c}0.027^{* *} \\
(0.012)\end{array}$ \\
\hline $\mathrm{HH}$ : There is domestic violence & $\begin{array}{l}0.15 \\
(0.33)\end{array}$ & $\begin{array}{l}-0.009 \\
(0.012)\end{array}$ & $\begin{array}{c}0.013 \\
(0.016)\end{array}$ \\
\hline HH: Two drunks fight on the street & $\begin{array}{l}0.14 \\
(0.35)\end{array}$ & $\begin{array}{l}-0.014 \\
(0.019)\end{array}$ & $\begin{array}{l}0.018 \\
(0.013)\end{array}$ \\
\hline HH: Kids fight on the street & $\begin{array}{l}-0.02 \\
(0.30)\end{array}$ & $\begin{array}{l}0.017 \\
(0.012)\end{array}$ & $\begin{array}{l}0.007 \\
(0.010)\end{array}$ \\
\hline HH: Home improvements affect neighbors & $\begin{array}{l}0.17 \\
(0.33)\end{array}$ & $\begin{array}{l}0.007 \\
(0.014)\end{array}$ & $\begin{array}{l}0.015 \\
(0.010)\end{array}$ \\
\hline HH: Someone is making noise & $\begin{array}{l}0.24 \\
(0.31)\end{array}$ & $\begin{array}{l}-0.002 \\
(0.013)\end{array}$ & $\begin{array}{l}0.006 \\
(0.007)\end{array}$ \\
\hline HH: People smoking marijuana near children & $\begin{array}{l}0.05 \\
(0.31)\end{array}$ & $\begin{array}{c}0.028^{* *} \\
(0.013)\end{array}$ & $\begin{array}{l}-0.012 \\
(0.012)\end{array}$ \\
\hline HH: Someone is mugged on the street & $\begin{array}{l}-0.02 \\
(0.34)\end{array}$ & $\begin{array}{c}0.000 \\
(0.013)\end{array}$ & $\begin{array}{l}0.020 \\
(0.013)\end{array}$ \\
\hline HH: A car or motorbike is stolen & $\begin{array}{l}0.06 \\
(0.35)\end{array}$ & $\begin{array}{l}-0.015 \\
(0.014)\end{array}$ & $\begin{array}{l}0.010 \\
(0.014)\end{array}$ \\
\hline HH: Someone is threatening someone else & $\begin{array}{l}0.00 \\
(0.33)\end{array}$ & $\begin{array}{l}0.002 \\
(0.017)\end{array}$ & $\begin{array}{l}0.017 \\
(0.010)\end{array}$ \\
\hline HH: It is necessary to prevent a theft & $\begin{array}{l}-0.01 \\
(0.35)\end{array}$ & $\begin{array}{l}0.022^{*} \\
(0.012)\end{array}$ & $\begin{array}{l}0.018^{*} \\
(0.010)\end{array}$ \\
\hline HH: You have to react to a robbery & $\begin{array}{l}0.02 \\
(0.37)\end{array}$ & $\begin{array}{l}0.001 \\
(0.015)\end{array}$ & $\begin{array}{c}0.019 \\
(0.011)\end{array}$ \\
\hline Biz: Someone does not want to pay a debt & $\begin{array}{l}-0.05 \\
(0.37)\end{array}$ & $\begin{array}{l}0.026 \\
(0.023)\end{array}$ & $\begin{array}{c}0.051^{* *} \\
(0.025)\end{array}$ \\
\hline Biz: Businesses in this sector are robbed & $\begin{array}{c}0.06 \\
(0.46)\end{array}$ & $\begin{array}{l}0.023 \\
(0.019)\end{array}$ & $\begin{array}{l}0.036 \\
(0.032)\end{array}$ \\
\hline Biz: Someone disturbs a business & $\begin{array}{l}0.13 \\
(0.45)\end{array}$ & $\begin{array}{l}0.022 \\
(0.023)\end{array}$ & $\begin{array}{l}0.035 \\
(0.029)\end{array}$ \\
\hline Biz: It is necessary to prevent a theft & $\begin{array}{l}0.10 \\
(0.47)\end{array}$ & $\begin{array}{l}0.038 \\
(0.023)\end{array}$ & $\begin{array}{l}0.033 \\
(0.030)\end{array}$ \\
\hline Biz: You have to react to a robbery & $\begin{array}{l}0.13 \\
(0.49)\end{array}$ & $\begin{array}{l}0.031 \\
(0.025)\end{array}$ & $\begin{array}{l}0.017 \\
(0.026)\end{array}$ \\
\hline Number of observations & & 570 & 563 \\
\hline
\end{tabular}

Notes: This table calculates the effect of being 100 meters further from the state on the 17 components of our governance indexes. HH indicates questions asked to households, and Biz represents questions asked to businesses. 
Table A.5: Heterogeneity analysis: Impacts on governance and legitimacy of being 100 meters closer to local state, by distance to original headquarters

\begin{tabular}{l}
\hline \\
\cline { 5 - 6 }
\end{tabular}

Table A.6: Heterogeneity: Impacts on being 100m closer to the state on neighborhood prosperity, by predicted drug profitability

\begin{tabular}{lccc}
\hline & & \multicolumn{2}{c}{ Economic Development Index } \\
\cline { 3 - 4 } & & Admin. outcomes & Survey outcomes \\
& Sample Mean & Estimate & Estimate \\
& $($ SD) & $($ SE) & $(3)$ \\
\hline Effect of moving 100m closer to state & $(1)$ & $(2)$ & -0.026 \\
& & $0.066^{*}$ & $(0.046)$ \\
100m closer to state X Predicted drug profitability (std.) & $(0.039)$ & 0.005 \\
& & -0.025 & $(0.045)$ \\
Predicted drug profitability (std.) & $(0.018)$ & 0.080 \\
& & 0.028 & $(0.142)$ \\
\hline \multirow{2}{*}{ Controls and fixed point running var } & $(0.094)$ & $\checkmark$ \\
Bi-directional Border FE & & $\checkmark$ & $\checkmark$ \\
$N$ & & $\checkmark$ & 228 \\
\hline
\end{tabular}

Notes: This table estimates Equation 7, regressing differences in our two main economic development indexes on the distance shock, a standardized measure of distance from the earliest drug plazas in Medellín (which emerged in the mid-2000s), and an interaction between the two. As a result, the coefficient on the distance shock estimates the treatment effect in neighborhoods at the average difference from drug plazas, and the coefficient on the interaction tells us how the impacts of the distance shock are different in neighborhoods far from early drug corners. 
Figure A.5: Placebo treatment effects, inner border, main analysis sample, 1,500 simulations.

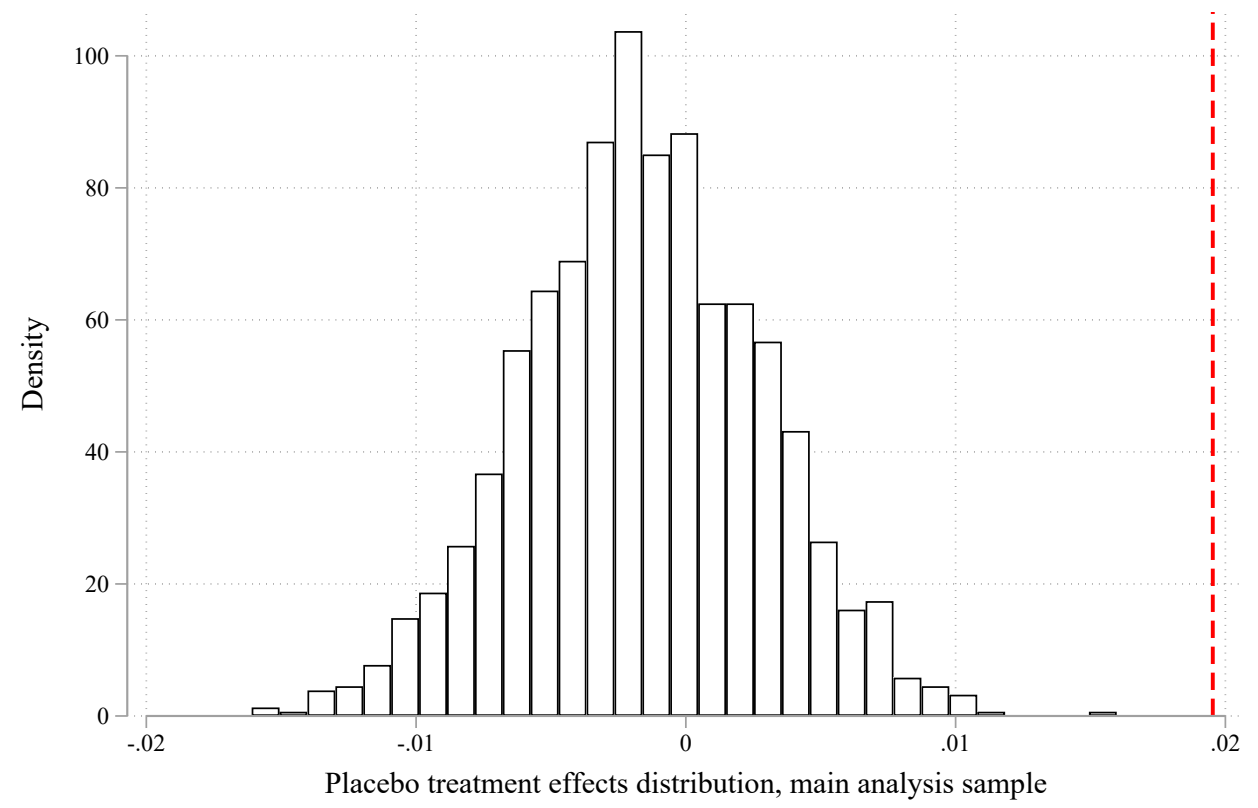

Notes: The figure depicts the distribution of average treatment effects of the difference in distance to the state on the difference in combo governance. Rather than matching pairs of blocks across the border, as in our main specification, we randomly matched our baseline sample of blocks with other blocks within the same comuna, using 1,500 simulations. We take blocks within 300 meters of the border and match them with blocks within a distance of at most 600 meters, resembling our baseline specification. The vertical line indicates our observed treatment effect. 


\section{Table A.7: Robustness of impacts on state and combo rule of being 100 meters closer to}

the local state

\begin{tabular}{|c|c|c|c|c|c|}
\hline & Median $\Delta d_{i j}$ & $\begin{array}{c}\Delta \text { State } \\
\text { Governance }\end{array}$ & $\begin{array}{c}\Delta \text { Combo } \\
\text { Governance }\end{array}$ & $\begin{array}{c}\Delta \text { State } \\
\text { Legitimacy }\end{array}$ & $\begin{array}{c}\Delta \text { Combo } \\
\text { Legitimacy }\end{array}$ \\
\hline & $\begin{array}{l}\text { Estimate } \\
\quad(\mathrm{SE})\end{array}$ & $\begin{array}{l}\text { Estimate } \\
\quad(\mathrm{SE})\end{array}$ & $\begin{array}{l}\text { Estimate } \\
\quad(\mathrm{SE})\end{array}$ & $\begin{array}{l}\text { Estimate } \\
\quad(\mathrm{SE})\end{array}$ & $\begin{array}{l}\text { Estimate } \\
\quad(\mathrm{SE})\end{array}$ \\
\hline & (1) & $(2)$ & $(3)$ & $(4)$ & $(5)$ \\
\hline Main specification & 4.128 & $\begin{array}{c}0.012^{*} \\
(0.007)\end{array}$ & $\begin{array}{c}0.020 * * * \\
(0.007)\end{array}$ & $\begin{array}{l}0.001 \\
(0.008)\end{array}$ & $\begin{array}{l}0.002 \\
(0.015)\end{array}$ \\
\hline Drop all control variables & 4.128 & $\begin{array}{c}0.013^{*} \\
(0.008)\end{array}$ & $\begin{array}{c}0.020 * * * \\
(0.007)\end{array}$ & $\begin{array}{l}-0.001 \\
(0.006)\end{array}$ & $\begin{array}{l}0.008 \\
(0.013)\end{array}$ \\
\hline Remove clustering & 4.128 & $\begin{array}{c}0.012^{* *} \\
(0.006)\end{array}$ & $\begin{array}{c}0.020 * * * \\
(0.007)\end{array}$ & $\begin{array}{l}0.001 \\
(0.005)\end{array}$ & $\begin{array}{c}0.002 \\
(0.008)\end{array}$ \\
\hline Border fixed effects & 4.128 & $\begin{array}{c}0.014^{*} \\
(0.008)\end{array}$ & $\begin{array}{c}0.014^{* *} \\
(0.006)\end{array}$ & $\begin{array}{c}0.007 \\
(0.007)\end{array}$ & $\begin{array}{c}0.003 \\
(0.013)\end{array}$ \\
\hline Matching to nearest block over any new border & 4.070 & $\begin{array}{c}0.014^{*} \\
(0.007)\end{array}$ & $\begin{array}{c}0.014^{*} \\
(0.007)\end{array}$ & $\begin{array}{c}0.000 \\
(0.006)\end{array}$ & $\begin{array}{l}0.002 \\
(0.012)\end{array}$ \\
\hline $200 \mathrm{~m}$ bandwith to border & 4.019 & $\begin{array}{c}0.012 \\
(0.007)\end{array}$ & $\begin{array}{c}0.021^{* *} \\
(0.009)\end{array}$ & $\begin{array}{c}0.006 \\
(0.008)\end{array}$ & $\begin{array}{l}0.004 \\
(0.018)\end{array}$ \\
\hline Drop the $25 \%$ of blocks closest to new border & 4.069 & $\begin{array}{c}0.011 \\
(0.008)\end{array}$ & $\begin{array}{c}0.025^{* * *} \\
(0.008)\end{array}$ & $\begin{array}{c}0.012^{*} \\
(0.006)\end{array}$ & $\begin{array}{c}0.007 \\
(0.011)\end{array}$ \\
\hline
\end{tabular}

Notes: This table compares alternative specifications, changing one feature of the model at a time. Each row is a different estimation of treatment effects. The unit of analysis is a pair of matched blocks on either side of a new border. The dependent variable is the difference in governance or legitimacy between the block pair. Each estimate in Column 2 comes from a regression of the dependent variable on the distance shock, controlling for other baseline bock-pair differences, a running variable to the border, and border fixed effects. Standard errors are clustered at the level of 42 nearby block-pair clusters that share a treatment direction. Only residents (not business respondents) were asked about legitimacy, and some blocks have only residents, hence the lower sample size. 


\section{B Formal presentation and extensions of model}

This section elaborates details of the model and several claims in Section 4.

\section{B.1 Cournot competition}

In our baseline setup, a state and a gang engage in Cournot competition with differentiated products. Cournot fits some of our stylized facts well-especially that governing requires investments and advanced commitments, and that it is hard to adjust output capacity quickly.

Setup In each neighborhood, a gang $g$ and a state $s$ compete to sell protection in quantities $q_{g}$ and $q_{s}$. Each organization chooses $q_{i}$ to maximize their respective pay-off, and each has constant marginal cost $c_{i}$. Products are differentiated, and the price of each one is given by the linear inverse demand function $p_{i}=a_{i}-\beta q_{i}-\gamma q_{j}$. Here, $\gamma \in(0,1]$ since the services

offered by both organizations are substitutes, and $\beta>0$ for downward-sloping demand. The pay-off for each organization is $V_{i}=p_{i} q_{i}-c_{i} q_{i}$. For simplicity, we assume an interior solution.

Nash Equilibria We begin by deriving the best response function for each organization:

$$
\begin{aligned}
\max _{q_{i}} V_{i} & =\left(a_{i}-\beta q_{i}-\gamma q_{j}\right) q_{i}-c_{i} q_{i} \\
\frac{\partial V_{i}}{\partial q_{i}} & =a_{i}-2 \beta q_{i}-\gamma q_{j}-c_{i}=0 \\
q_{i}^{*} & =\frac{a_{i}-c_{i}}{2 \beta}-\frac{\gamma}{2 \beta} q_{j}
\end{aligned}
$$

We obtain an identical best response function for the other organization analogously, and replacing values we obtain:

$$
q_{i}^{*}=\frac{2 \beta\left(a_{i}-c_{i}\right)-\gamma\left(a_{j}-c_{j}\right)}{\left(4 \beta^{2}-\gamma^{2}\right)}
$$

and,

$$
q_{j}^{*}=\frac{2 \beta\left(a_{j}-c_{j}\right)-\gamma\left(a_{i}-c_{i}\right)}{\left(4 \beta^{2}-\gamma^{2}\right)}
$$


Comparative statics We are mainly interested in whether gang rule is crowded in or out when there is an exogenous increase in state governance: $\frac{\partial q_{i}^{*}}{\partial q_{j}}$. To obtain this comparative static, we begin by defining:

$$
G\left(q_{i}, q_{j}\right) \equiv \frac{\partial V_{i}}{\partial q_{i}}=a_{i}-2 \beta q_{i}-\gamma q_{j}-c_{i}
$$

which is a continuously differentiable function from $\mathbb{R}^{2} \rightarrow \mathbb{R}$. At the optimum, we know:

$$
G\left(q_{i}^{*}, q_{j}^{*}\right)=a_{i}-2 \beta_{i} q_{i}^{*}-\gamma q_{j}^{*}-c_{i}=0
$$

Since $-2 \beta \neq 0$, we can use the implicit function theorem to obtain our main comparative static:

$$
\frac{\partial q_{i}^{*}}{\partial q_{j}}=-\frac{\partial G\left(q_{i}, q_{j}\right) / \partial q_{j}}{\partial G\left(q_{i}, q_{j}\right) / \partial q_{i}}=-\frac{\gamma}{2 \beta}
$$

Since the two services are not complements, this comparative static implies that increases in one duopolist's supply of protection will reduce the other's.

\section{Cournot competition with benefits to governing}

We now introduce a non-standard feature: externalities stemming from gang rule.

Setup As above, but now the payoff for each organization is $V_{i}=\left(a_{i}-\beta_{i} q_{i}-\gamma q_{j}\right) q_{i}-c_{i} q_{i}+$ $\rho\left(q_{i}, q_{j}\right) \pi_{i}$, where $\rho\left(q_{i}, q_{j}\right) \pi_{i}$ captures the externalities described in Section 4. For simplicity, we assume an interior solution.

Nash Equilibria We begin by deriving the best response function for each organization:

$$
\begin{aligned}
\max _{q_{i}} V_{i} & =\left(a_{i}-\beta q_{i}-\gamma q_{j}\right) q_{i}-c_{i} q_{i}+\rho\left(q_{i}, q_{j}\right) \pi_{i} \\
\frac{\partial V_{i}}{\partial q_{i}} & =a_{i}-2 \beta q_{i}-\gamma q_{j}-c_{i}+\frac{\partial \rho\left(q_{i}, q_{j}\right)}{\partial q_{i}} \pi_{i}=0 \\
q_{i}^{*} & =\frac{a_{i}-c_{i}+\frac{\partial \rho\left(q_{i}, q_{j}\right)}{\partial q_{i}} \pi_{i}}{2 \beta}-\frac{\gamma}{2 \beta} q_{j}
\end{aligned}
$$

We obtain an identical best response function for the other organization analogously, and replacing values we obtain: 


$$
q_{i}^{*}=\frac{2 \beta\left(a_{i}-c_{i}\right)-\gamma\left(a_{j}-c_{j}\right)+\left(2 \beta \frac{\partial \rho\left(q_{i}, q_{j}\right)}{\partial q_{i}} \pi_{i}-\gamma \frac{\partial \rho\left(q_{i}, q_{j}\right)}{\partial q_{j}} \pi_{j}\right)}{\left(4 \beta^{2}-\gamma^{2}\right)}
$$

with an analogous function for $q_{j}^{*}$.

Comparative statics Again we are interested in whether gang rule is crowded in or out when there is an exogenous increase in state governance: $\frac{\partial q_{i}^{*}}{\partial q_{j}}$. To obtain this comparative static, we begin by defining:

$$
G\left(q_{i}, q_{j}\right) \equiv \frac{\partial V_{i}}{\partial q_{i}}=a_{i}-2 \beta q_{i}-\gamma q_{j}-c_{i}+\frac{\partial \rho\left(q_{i}, q_{j}\right)}{\partial q_{i}} \pi_{i}
$$

which is a continuously differentiable function from $\mathbb{R}^{2} \rightarrow \mathbb{R}$. At the optimum, we know:

$$
G\left(q_{i}^{*}, q_{j}^{*}\right)=a_{i}-2 \beta q_{i}^{*}-\gamma q_{j}^{*}-c_{i}+\frac{\partial \rho\left(q_{i}^{*}, q_{j}^{*}\right)}{\partial q_{i}} \pi_{i}=0
$$

Additionally, we assume that $2 \beta \neq \frac{\partial^{2} \rho\left(q_{i}^{*}, q_{j}^{*}\right)}{\partial q_{i} \partial q_{i}} \pi_{i}$, thus:

$$
\frac{\partial G\left(q_{i}^{*}, q_{j}^{*}\right)}{\partial q_{i}}=-2 \beta+\frac{\partial^{2} \rho\left(q_{i}^{*}, q_{j}^{*}\right)}{\partial q_{i} \partial q_{i}} \pi_{i} \neq 0
$$

We can use the implicit function theorem to obtain our main comparative static:

$$
\frac{\partial q_{i}^{*}}{\partial q_{j}}=-\frac{\partial G\left(q_{i}, q_{j}\right) / \partial q_{j}}{\partial G\left(q_{i}, q_{j}\right) / \partial q_{i}}=\frac{\lambda \pi_{i}-\gamma}{2 \beta-\delta \pi_{i}}
$$

where $\lambda=\frac{\partial^{2} \rho\left(q_{i}, q_{j}\right)}{\partial q_{i} \partial q_{j}}$ represents the cross-partial derivative between gang and state governance, and $\delta=\frac{\partial^{2} \rho\left(q_{i}, q_{j}\right)}{\partial q_{i} \partial q_{i}}$ reflects the rate of increasing or decreasing returns to governing. We discuss conditions for this comparative static to be positive in section 4 .

\section{B.2 Cournot competition with endogenous demand}

We now consider the possibility that providing governance can produce economic growth, which in turn may produce greater demand for governance. This section incorporates this idea into the Cournot framework by "endogenizing demand." The next section considers a political economy model in which "stationary bandits" provide public goods in order to grow the economic pie that they will tax. 
Setup As before, except we now generalize the functional form of demand such that products are differentiated so the price of each one is determined by $p_{i}=a_{i}\left(q_{i}, q_{j}\right)-\beta q_{i}-\gamma q_{j}$, where $\gamma \in(0,1]$ as services provided by both organizations are substitutes, and $a_{i}\left(q_{i}, q_{j}\right)$ is twice continuously differentiable. The payoff function is $V_{i}=\left(a_{i}\left(q_{i}, q_{j}\right)-\beta q_{i}-\gamma q_{j}\right) q_{i}-c_{i} q_{i}+$ $\rho\left(q_{i}, q_{j}\right) \pi_{i}$, where $\rho\left(q_{i}, q_{j}\right) \pi_{i}$ captures the externalities described above in section B.1. Again, we assume an interior solution.

Nash Equilibria As above, we begin by deriving the best response function for each organization:

$$
\begin{aligned}
\max _{q_{i}} V_{i} & =\left(a_{i}\left(q_{i}, q_{j}\right)-\beta q_{i}-\gamma q_{j}\right) q_{i}-c_{i} q_{i}+\rho\left(q_{i}, q_{j}\right) \pi_{i} \\
\frac{\partial V_{i}}{\partial q_{i}} & =a_{i}\left(q_{i}, q_{j}\right)+\frac{\partial a_{i}\left(q_{i}, q_{j}\right)}{\partial q_{i}} q_{i}-2 \beta q_{i}-\gamma q_{j}-c_{i}+\frac{\partial \rho\left(q_{i}, q_{j}\right)}{\partial q_{i}} \pi_{i}=0 \\
q_{i}^{*} & =\frac{a_{i}\left(q_{i}, q_{j}\right)-c_{i}+\frac{\partial \rho\left(q_{i}, q_{j}\right)}{\partial q_{i}} \pi_{i}}{2 \beta-\frac{\partial a_{i}\left(q_{i}, q_{j}\right)}{\partial q_{i}}}-\frac{\gamma}{2 \beta-\frac{\partial a_{i}\left(q_{i}, q_{j}\right)}{\partial q_{i}}} q_{j}
\end{aligned}
$$

We obtain an identical best response function for the other organization analogously, and replacing values we obtain:

$$
q_{i}^{*}=\frac{\left.\left.\left(a_{i}\left(q_{i}, q_{j}\right)-c_{i}+\frac{\partial \rho\left(q_{i}, q_{j}\right)}{\partial q_{i}} \pi_{i}\right)\right)\left(2 \beta-\frac{\partial a_{j}\left(q_{i}, q_{j}\right)}{\partial q_{j}}\right)-\gamma\left(a_{j}\left(q_{i}, q_{j}\right)-c_{j}+\frac{\partial \rho\left(q_{i}, q_{j}\right)}{\partial q_{j}} \pi_{j}\right)\right)}{\left(2 \beta-\frac{\partial a_{i}\left(q_{i}, q_{j}\right)}{\partial q_{i}}\right)\left(2 \beta-\frac{\partial a_{j}\left(q_{i}, q_{j}\right)}{\partial q_{j}}\right)+\gamma^{2}}
$$

and similarly for $q_{j}^{*}$.

Comparative Statics To obtain the key comparative static, we define

$$
G\left(q_{i}, q_{j}\right) \equiv \frac{\partial V_{i}}{\partial q_{i}}=a_{i}\left(q_{i}, q_{j}\right)+\frac{\partial a_{i}\left(q_{i}, q_{j}\right)}{\partial q_{i}} q_{i}-2 \beta q_{i}-\gamma q_{j}-c_{i}+\frac{\partial \rho\left(q_{i}, q_{j}\right)}{\partial q_{i}} \pi_{i}
$$

which is a continuously differentiable function from $\mathbb{R}^{2} \rightarrow \mathbb{R}$. At the optimum, we know that $G\left(q_{i}^{*}, q_{j}^{*}\right)=0$. We also assume that $\frac{\partial G\left(q_{i}^{*}, q_{j}^{*}\right)}{\partial q_{i}} \neq 0$.

Then, we can use the implicit function theorem to obtain our main comparative static in the formulation with endogenous demand. Note this implies that there is a neighborhood of $\left(q_{i}^{*}, q_{j}^{*}\right)$ such that when $q_{i}$ is close enough to $q_{i}^{*}$, we have a unique $q_{j}$ such as $G\left(q_{i}, q_{j}\right)=0$, which makes $q_{j}$ a continuous function of $q_{i}$. The comparative static is: 


$$
\frac{\partial q_{i}}{\partial q_{j}}=-\frac{\partial G\left(q_{i}, q_{j}\right) / \partial q_{j}}{\partial G\left(q_{i}, q_{j}\right) / \partial q_{i}}=-\frac{\frac{\partial a_{i}\left(q_{i}, q_{j}\right)}{\partial q_{j}}+\frac{\partial^{2} a_{i}\left(q_{i}, q_{j}\right)}{\partial q_{i} \partial q_{j}} q_{i}-\gamma+\frac{\partial^{2} \rho\left(q_{i}, q_{j}\right)}{\partial q_{i} \partial q_{j}} \pi_{j}}{2 * \frac{\partial a_{i}\left(q_{i}, q_{j}\right)}{\partial q_{i}}+\frac{\partial^{2} a_{i}\left(q_{i}, q_{j}\right)}{\partial q_{i} \partial q_{i}} q_{i}-2 \beta+\frac{\partial^{2} \rho\left(q_{i}, q_{j}\right)}{\partial q_{i} \partial q_{i}} \pi_{i}}
$$

Now, a sufficient condition for having a positive cross partial is that $a_{i}(\cdot)$ is downward sloping on the product $\left(\frac{\partial a_{i}\left(q_{i}, q_{j}\right)}{\partial q_{i}}<0\right)$, that the decrease is at decreasing rates $\left(\frac{\partial^{2} a_{i}\left(q_{i}, q_{j}\right)}{\partial q_{i} \partial q_{i}}<0\right)$, that the loyalty function is concave $\left(\frac{\partial^{2} \rho\left(q_{i}, q_{j}\right)}{\partial q_{i} \partial q_{i}}<0\right)$, and that $\frac{\partial a_{i}\left(q_{i}, q_{j}\right)}{\partial q_{j}}+\frac{\partial^{2} a_{i}\left(q_{i}, q_{j}\right)}{\partial q_{i} \partial q_{j}} q_{i}-\gamma+$ $\frac{\partial^{2} \rho\left(q_{i}, q_{j}\right)}{\partial q_{i} \partial q_{j}}>0$. The interpretation of the last condition would depend on what captures $a_{i}(\cdot)$.

\section{B.3 Bertrand competition with differentiated products}

Now we model a state and a gang engaging in Bertrand competition with differentiated products and externalities from gang governance. Each organization has a certain valuation of the loyalty of the people.

Setup A gang $g$ and a state $s$ compete over prices $p_{g}$ and $p_{s}$. Each organization chooses to maximize their respective pay-off based on parameters. Both organizations have a constant marginal cost $c$. Products are differentiated so the quantity demanded of each one is given by $q_{i}=a_{i}-b_{i} p_{i}-\gamma p_{j}$, where $\gamma<0$ as goods produced by both organizations are assumed to be substitutes. The pay-off for each organization is $\nu_{i}=\left(a_{i}-b_{i} p_{i}-\gamma p_{j}\right)\left(p_{i}-c\right)+F\left(p_{i}, p_{j}\right)$, where $F\left(p_{i}, p_{j}\right)$ captures externalities. For simplicity, we assume an interior solution.

Nash Equilibria We begin by deriving the best response function for each organization:

$$
\begin{aligned}
\max _{p_{i}} \nu_{i} & =\left(a_{i}-b_{i} p_{i}-\gamma p_{j}\right)\left(p_{i}-c\right)+F\left(p_{i}, p_{j}\right) \\
\frac{\partial \nu_{i}}{\partial p_{i}} & =\left(a_{i}-2 b_{i} p_{i}-\gamma p_{j}-b_{i} c\right)+\frac{\partial F\left(p_{i}, p_{j}\right)}{\partial p_{i}}=0 \\
p_{i}^{*} & =\frac{\left(a_{i}-b_{i} c+\frac{\partial F\left(p_{i}, p_{j}\right)}{\partial p_{i}}\right)}{2 b_{i}}-\frac{\gamma p_{j}}{2 b_{i}}
\end{aligned}
$$

Analogously, we obtain a best response function for the other organization. Replacing values we obtain:

$$
p_{i}^{*}=\frac{2 b_{j} a_{i}-\gamma a_{j}-\left(2 b_{j} b_{i}-\gamma b_{j}\right) c+2 b_{j} \frac{\partial F\left(p_{i}^{*}, p_{j}^{*}\right)}{\partial p_{i}}-\gamma \frac{\partial F\left(p_{j}^{*}, p_{i}^{*}\right)}{\partial p_{j}}}{\left(4 b_{i} b_{j}-\gamma^{2}\right)}
$$


Comparative statics To obtain our key comparative static, we define:

$$
M\left(p_{i}, p_{j}\right) \equiv \frac{\partial \nu_{i}}{\partial p_{i}}=\left(a_{i}-2 b_{i} p_{i}-\gamma p_{j}-b_{i} c\right)+\frac{\partial F\left(p_{i}, p_{j}\right)}{\partial p_{i}}
$$

which is a continuously differentiable function. In the optimum we know that:

$$
M\left(p_{i}^{*}, p_{j}^{*}\right)=\frac{\partial \nu_{i}}{\partial p_{i}}=\left(a_{i}-2 b_{i} p_{i}^{*}-\gamma p_{j}^{*}-b_{i} c\right)+\frac{\partial F\left(p_{i}^{*}, p_{j}^{*}\right)}{\partial p_{i}}=0
$$

Additionally, we assume that $2 b_{i} \neq \frac{\partial^{2} F\left(p_{i}^{*}, p_{j}^{*}\right)}{\partial p_{i} \partial p_{i}}$, so:

$$
\frac{\partial M\left(p_{i}^{*}, p_{j}^{*}\right)}{\partial p_{i}}=-2 b_{i}+\frac{\partial^{2} F\left(p_{i}^{*}, p_{j}^{*}\right)}{\partial p_{i} \partial p_{i}} \neq 0
$$

Then we can use the implicit function theorem, obtaining the following result:

$$
\frac{\partial p_{i}}{\partial p_{j}}=-\frac{\partial M / \partial p_{j}}{\partial M / \partial p_{i}}=-\frac{\gamma-\frac{\partial^{2} F\left(p_{i}^{*}, p_{j}^{*}\right)}{\partial p_{i} \partial p_{j}}}{2 b_{i}-\frac{\partial^{2} F\left(p_{i}^{*}, p_{j}^{*}\right)}{\partial p_{i} \partial p_{i}}}
$$

Thus, to have a crowding in effect $\left(\frac{\partial p_{i}}{\partial p_{j}}>0\right)$ we require that $\gamma<\frac{\partial^{2} F\left(p_{i}^{*}, p_{j}^{*}\right)}{\partial p_{i} \partial p_{j}}$. Since $\gamma<0$, a sufficient condition for the state to crowd in the gang is that both services are complements in loyalty. Generally, it is enough that the complementarity in loyalty is higher than the degree of substitution of these services.

\section{B.4 Public goods and encompassing interest}

Section B.2 showed how state-provided protection and governance may "grow the pie", and how this can be incorporated into standard models of duopolistic competition. This idea lies at the very heart of standard political economy of governance and public-goods provision. This section adapts the classic Olson and McGuire (1996) (henceforth OM) model, in which stationary bandits face incentives to curtail their own coercive taxation and provide public goods at their own expense, precisely because doing so grows the pie that the bandit later taxes. We abstract from OM's comparison of autocracy and democracy, instead comparing the baseline OM model of a monopolistic, autocratic stationary bandit to a modified version in which two stationary bandits tax and provide public goods to the same subject population. A simple two-bandit model predicts crowding out. We first illustrate the single-bandit baseline model and then add the second stationary bandit. 


\section{Baseline: One Autocratic Stationary Bandit}

- One player: The state $(S)$ makes two independent choices, setting a level of public goods provision $\left(G_{s}\right)$ and a uniform tax rate $t_{s} \in[0,1]$.

- The output of the economy $Y$ is increasing convexly in the total amount of public goods provided $G$ (which here equals $G_{S}$ since there is only one stationary bandit), and no production is possible without some amount of public goods. That is, for $Y(G)$ we assume $Y(0)=0, \frac{\partial Y(G)}{\partial G}>0$, and $\frac{\partial^{2} Y(G)}{\partial G^{2}}<0$.

- We assume that taxation distorts economic activity. Write $\tau\left(t_{s}\right) \in[0,1]$ represent the loss factor due to taxation, so that final GDP is equal to $\tau\left(t_{s}\right) * Y\left(G_{s}\right)$. We assume $\frac{\partial \tau\left(t_{s}\right)}{\partial t_{s}}<0$

The state maximization problem is given by:

$$
V_{s}=\tau\left(t_{s}\right) \cdot t_{s} \cdot Y(G)-c G_{s}
$$

For simplicity, we normalize $c$ to 1 . By construction, $S$ sets taxes independently of the desired level of public good. At the optimal $t_{s}^{*}, S^{\prime}$ 's gains from taxation and the increases of potential output losses due to further distortion into the economy are $\tau\left(t_{s}\right) * t_{s}=\frac{\partial \tau\left(t_{s}\right)}{\partial t_{s}}$. This can be seen in the first order conditions for Equation 9:

$$
\begin{gathered}
\frac{\partial V_{s}}{\partial t_{s}}=\left(\tau\left(t_{s}\right)+t_{s} \frac{\partial \tau\left(t_{s}\right)}{\partial t_{s}}\right) \cdot Y\left(G_{s}\right)=0 \\
\tau\left(t_{s}\right)+t_{s} \frac{\partial \tau\left(t_{s}\right)}{\partial t_{s}}=0 \\
t_{s}^{*}=-\frac{\tau\left(t_{s}\right)}{\frac{\partial \tau\left(t_{s}\right)}{\partial t_{s}}}
\end{gathered}
$$

Finally, the state selects the level of public good in the point were the marginal revenue is equal to the marginal cost of the public good $c$ multiplied by the reciprocal of state's share of the national potential income.

$$
\frac{\partial V_{s}}{\partial G_{s}}=\tau\left(t_{s}\right) \cdot t_{s} \cdot Y^{\prime}\left(G_{s}\right)-1=0
$$




$$
Y^{\prime}\left(G_{S}^{*}\right)=\frac{1}{t_{s}^{*} \tau\left(t_{s}^{*}\right)}
$$

\section{Dual stationary bandits}

The setup is similar but with two players, a state $(s)$ and gang $(g)$.

- Players $i \in\{s, g\}$ simultaneously choose levels of public-goods provision $\left(G_{i}\right)$ and a uniform tax rate $\left(t_{i}\right)$ which, as before, is independent of public-goods provision.

- Economic output depends on the total of the two actors' public good provision: $Y(G)$ where $G \equiv G_{s}+G_{g}$. As before, $Y(0)=0, \frac{\partial Y(G)}{\partial G}>0$ and $\frac{\partial^{2} Y(G)}{\partial G \partial G}<0$

- Distortion $\tau(t)$ depends on the total amount of taxes levied: $t \equiv t_{s}+t_{g}$. As before: $\tau(0)=1$ and $\frac{\partial \tau}{\partial t}<0$.

- To ensure that neither player sets $t_{i}>.5$, we assume that $\tau(.5)=0$.

Players' utility functions and maximization problems are symmetrical:

$$
V_{i}=t_{i} \cdot \tau\left(t_{i}+t_{j}\right) \cdot Y\left(G_{i}+G_{j}\right)-c_{i} G_{i} \text { for } i, j \in\{s, g\}
$$

In this simplest, symmetric-players iteration, we will assume that $c_{i}=c_{j}=1$. Asymmetric costs raise important questions of sequencing, and will be considered in future iterations. As before, we solve the two maximization problems separately, starting with taxation.

\section{Optimal taxation with dual stationary bandits}

Lemma B.1. In equilibrium, players' optimal tax rates are identical: $t_{i}^{*}=t_{j}^{*}$.

Proof. From equation (12), the first order condition for player $i$ is:

$$
\begin{array}{rlc}
\frac{\partial V_{i}}{\partial t_{i}} & = & \tau\left(t_{i}+t_{j}\right) Y(G)+t_{i} \frac{\partial \tau\left(t_{i}+t_{j}\right)}{\partial t_{i}} Y(G)=0 \\
& = & \tau\left(t_{i}^{*}+t_{j}^{*}\right)+t_{i} \frac{\partial \tau\left(t_{i}+t_{j}\right)}{\partial t_{i}}=0
\end{array}
$$

We can rewrite $\frac{\partial \tau\left(t_{i}+t_{j}\right)}{\partial t_{i}}$ as $\frac{\partial \tau\left(t_{i}+t_{j}\right)}{\partial t} \frac{\partial t}{\partial t_{i}}=\frac{\partial \tau\left(t_{i}+t_{j}\right)}{\partial t}=\tau^{\prime}(t)$. This yields:

$$
t_{i}^{*}\left(t_{j}\right)=-\frac{\tau\left(t_{i}^{*}+t_{j}\right)}{\tau^{\prime}\left(t_{i}^{*}+t_{j}\right)}
$$


By a similar derivation, $t_{j}^{*}\left(t_{i}\right)=-\frac{\tau\left(t_{i}+t_{j}^{*}\right)}{\tau^{\prime}\left(t_{i}+t_{j}^{*}\right)}$

So in Nash Equilibrium:

$$
t_{i}^{*}=-\frac{\tau\left(t_{i}^{*}+t_{j}^{*}\right)}{\tau^{\prime}\left(t_{i}^{*}+t_{j}^{*}\right)}=t_{j}^{*}
$$

In words, when $i$ increases $t_{i}$ they get a larger share of a smaller pie. These two effects must be of equal size at the optimum $t_{i}^{*}$. But the negative effect on the size of the pie is the same whether $i$ or $j$ is raising their rate. Therefore, the increase in $i^{\prime} s$ share at $t_{i}^{*}$ must be the same as the change in $j^{\prime} s$ share if they were to raise their rate. But these "shares" are just each player's tax rate. So these must be equal.

Optimal public-goods provision with dual stationary bandits In this simultaneous setup, we identify Nash equilibria in which player $i$ 's choice of $G_{i}$ is a best response to player $j$ 's choice of $G_{j}$ and vice versa. Solving the first order conditions for equation (12) for $G_{i}$ and $G_{j}$ yields

$$
\begin{aligned}
\max _{0 \leq G_{i}} V_{i} & =t_{i} \cdot \tau\left(t_{i}+t_{j}\right) \cdot Y\left(G_{i}+G_{j}\right)-c_{i} G_{i} \\
\frac{\partial V_{i}}{\partial G_{i}} & =t_{i} \tau\left(t_{i}+t_{j}\right) Y^{\prime}\left(G_{i}+G_{j}\right)-c_{i} \leq 0
\end{aligned}
$$

where the last condition hold with equality if $G_{i}>0$. We can write player $i$ 's best response function implicitly (i.e., $i$ wants to set $G_{i}^{*}$ such that):

$$
G_{i}^{*}\left(G_{j}\right): Y^{\prime}\left(G_{i}^{*}+G_{j}\right) \leq \frac{c_{i}}{t_{i}^{*} \tau\left(t_{i}^{*}+t_{j}^{*}\right)}
$$

and player $j$ wants to set $G_{j}^{*}$ such that

$$
G_{j}^{*}\left(G_{i}\right): Y^{\prime}\left(G_{i}+G_{j}^{*}\right) \leq \frac{c_{j}}{t_{j}^{*} \tau\left(t_{j}^{*}+t_{j}^{*}\right)}
$$

If we assume $c_{i}=c_{j}=c$ and with no loss of generality that $c=1$ then (because $t_{i}^{*}=t_{j}^{*}$ ) there is a unique total $G$ that is optimal for both players, call it $G_{2 B}^{*}$ :

$$
Y^{\prime}\left(G_{2 B}^{*}\right)=\frac{1}{t_{i}^{*} \tau\left(t_{j}^{*}+t_{j}^{*}\right)}
$$

And there is a continuum of Nash equilibria characterized by $G_{i}^{*}=G_{2 B}^{*}-G_{j}^{*}$. Obviously, the cross-partial of this relationship, $\frac{\partial G_{i}^{*}}{\partial G_{j}^{*}}$ is negative. 
In words, there is an optimal total amount of public-goods to be provided, and either player is happy to provide goods until total goods supplied reached that optimum. Obviously, each prefers that the other do it. But for any division of the optimal total amount between the two players, neither has an incentive to deviate. Furthermore, if some force outside the model pushed the result from one equilibrium to another, in which one player's public goods provision increased, it is obvious that the other player's optimal response would decrease.

In this way, the basic stationary bandit model, which explicitly accounts for economic growth produced by governance provision, can be said to predict crowding out.

\section{B.5 General formulation and alternative models}

Here we abstract away from the examples of Cournot and Bertrand competition, or stationary bandits above. Instead of modeling competition with one model or the other, we could use a general form $D\left(q_{i}, q_{j}\right)$ that encompasses all of these models (including Bertrand). Likewise, instead of modeling the externality as $\rho\left(q_{i}, q_{j}\right) \pi_{i}$ we use a general form $F\left(q_{i}, q_{j}\right)$.

Comparative statics We now define a value function where we are agnostic about how duopolistic competition takes place:

$$
V_{i}=D\left(q_{i}, q_{j}\right)+F\left(q_{i}, q_{j}\right)
$$

Then we can define the first partial in $q_{i}$ as:

$$
G\left(q_{i}, q_{j}\right) \equiv \frac{\partial V_{i}}{\partial q_{i}}=\frac{\partial D\left(q_{i}, q_{j}\right)}{\partial q_{i}}+\frac{\partial F\left(q_{i}, q_{j}\right)}{\partial q_{i}}
$$

which is a continuously differentiable function from $\mathbb{R}^{2} \rightarrow \mathbb{R}$. As a technical note, we assume that there exists a point such that $\frac{\partial V_{i}}{\partial q_{i}}=0$, and the functions $D(\cdot)$ and $F(\cdot)$ are concave so that the sum of both functions is also concave. This implies there is a unique solution. At the optimum, we know that $G\left(q_{i}^{*}, q_{j}^{*}\right)=0$. We also assume that $\frac{\partial G\left(q_{i}^{*}, q_{j}^{*}\right)}{\partial q_{i}} \neq 0$.

Finally, we can use the implicit function theorem to obtain our main comparative static in the general formulation. Note this implies that there is a neighborhood of $\left(q_{i}^{*}, q_{j}^{*}\right)$ such that when $q_{i}$ is close enough to $q_{i}^{*}$, we have a unique $q_{j}$ such that $G\left(q_{i}, q_{j}\right)=0$. This makes $q_{j}$ a continuous function of $q_{i}$. The comparative static is:

$$
\frac{\partial q_{i}}{\partial q_{j}}=-\frac{\partial G\left(q_{i}, q_{j}\right) / \partial q_{j}}{\partial G\left(q_{i}, q_{j}\right) / \partial q_{i}}=-\frac{\frac{\partial^{2} D\left(q_{i}, q_{j}\right)}{\partial q_{i} \partial q_{j}}+\frac{\partial^{2} F\left(q_{i}, q_{j}\right)}{\partial q_{i} \partial q_{j}}}{\frac{\partial^{2} D\left(q_{i}, q_{j}\right)}{\partial q_{i} \partial q_{i}}+\frac{\partial^{2} F\left(q_{i}, q_{j}\right)}{\partial q_{i} \partial q_{i}}}
$$


where $\frac{\partial^{2} D\left(q_{i}, q_{j}\right)}{\partial q_{i} \partial q_{i}} \leq 0, \frac{\partial^{2} F\left(q_{i}, q_{j}\right)}{\partial q_{i} \partial q_{i}} \leq 0$ would mean decreasing returns of production in loyalty and profit. With this assumption, a positive numerator is sufficient for a positive cross partial. 


\section{Measurement error}

\section{C.1 Survey experiments}

In this appendix, we study how measurement error can affect the interpretation of our results. Figure C.1 and Table C.1 report the results of our survey experiments and analysis of measurement error (discussed in Section 6.5).

\section{C.2 Measurement error models}

Finally, we show that several forms of measurement error would lead us to underestimate the effect of the distance shock. We focus on three types of measurement error: reporting endogenous to gang rule, reporting endogenous to relative state governance, and reporting endogenous to both gang and state governance separately. In each case, we study how the reporting error changes the coefficient we estimate in the main results of the paper, and discuss the direction of the bias it induces.

Reporting endogenous to gang rule Suppose the true relationship between combo and state governance is given by:

$$
g_{c}^{*}=\alpha+\beta g_{s}^{*}+\epsilon
$$

However, suppose $g_{c}^{*}$ is systematically under-reported in the survey at a rate proportional to combo governance, as follows:

$$
g_{c}=g_{c}^{*}+\mu
$$

Where $0<\delta<1$ is the reporting rate of gang governance. Then:

$$
\frac{g_{c}-\mu}{\delta}=\alpha+\beta g_{s}^{*}+\epsilon
$$

and hence we would estimate:

$$
g_{c}=\delta \alpha+\delta \beta g_{s}^{*}+\nu
$$

Where $\nu=\delta \epsilon+\mu$. Usingh observed data we will estimate $\hat{\delta \beta}<\beta$, which means that we underestimate the crowding out/in coefficient of gang governance. 
Figure C.1: Survey experiment results: Difference between randomized response (RR) and direct response (DR) to security fee payment rate

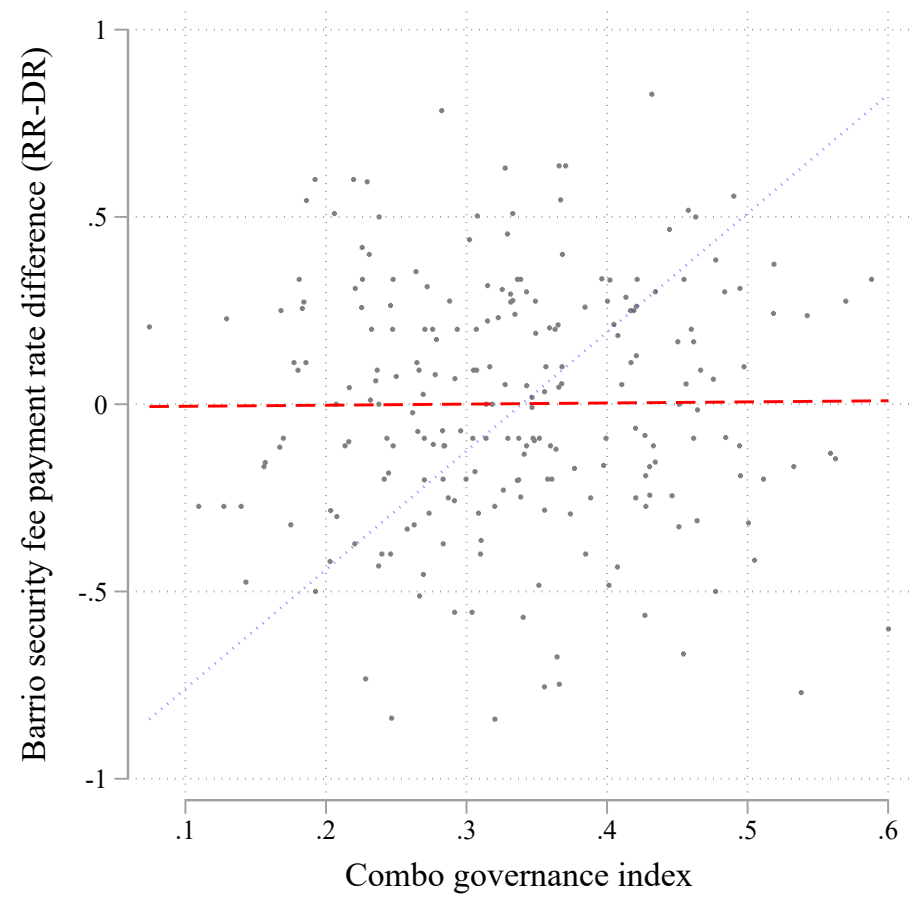

Notes: Each dot represents a barrio average. The dotted line indicates fitted values. We did not survey high-income barrios. 
Table C.1: Test of systematic measurement error: Coefficient of closeness to state services for blocks along the inner comuna borders of Medellín on measurement error proxies

\begin{tabular}{|c|c|c|}
\hline \multirow{3}{*}{ Effect on $\Delta Y$} & & $\begin{array}{l}\text { Effect of moving } \\
100 \mathrm{~m} \text { closer to state }\end{array}$ \\
\hline & $\begin{array}{c}\text { Subsample } \\
\text { Mean } \\
\text { (SD) }\end{array}$ & $\begin{array}{l}\text { Estimate } \\
\quad(\mathrm{SE})\end{array}$ \\
\hline & $(1)$ & $(2)$ \\
\hline Extortion payment rate difference (RR-DR) & $\begin{array}{l}-0.06 \\
(0.82)\end{array}$ & $\begin{array}{l}-0.061 \\
(0.059)\end{array}$ \\
\hline Proportion of questions answered for state & $\begin{array}{c}0.90 \\
(0.13)\end{array}$ & $\begin{array}{l}-0.005 \\
(0.008)\end{array}$ \\
\hline Proportion of questions answered for combo & $\begin{array}{c}0.85 \\
(0.18)\end{array}$ & $\begin{array}{c}-0.021^{*} \\
(0.012)\end{array}$ \\
\hline Number of observations & & 573 \\
\hline Minimum N & & 249 \\
\hline
\end{tabular}

Notes: This table examines the correlation between proxies for measurement error and being 100 meters more distant from the state, using the same estimation for our main treatment effects. The extortion rate difference computes the difference between randomized response and direct response to the question of whether the household pays extortion. The other measures capture non-response to sensitive items (the proportion of questions answered). We look at the proportion of questions answered for each index, and whether this is different for the state versus the combo. More questions answered for the state could indicate a reluctance to talk about or disclose combo activities. 
Reporting endogenous to relative state governance Now let's continue to the same true relationship between $g_{c}^{*}$ and $g_{c}^{*}$, but now under-reporting depends on relative state/combo governance:

$$
g_{c}=\lambda\left(g_{c}^{*}-g_{s}^{*}\right)+\mu
$$

Where $0<\lambda<1$ is the reporting rate of relative state governance. Then:

$$
g_{c}^{*}=\frac{1}{\lambda} g_{c}+g_{s}^{*}-\frac{\mu}{\lambda}
$$

and hence we would estimate:

$$
g_{c}=\lambda \alpha+\lambda(\beta-1) g_{s}^{*}+\eta
$$

Where $\eta=\lambda \epsilon+\mu$. Using oberved data we will estimate $\lambda(\hat{\beta-1})<\beta$, which means that we, again, underestimate the crowding out/in coefficient of gang governance.

Reporting endogenous to gang and state governance, separately Now suppose we let reported gang governance depends on actual gang and state governance, where reporting rates are different can be different in each case:

$$
g_{c}=\delta g_{c}^{*}+\lambda g_{s}^{*}+\mu
$$

Where both: $0<\lambda<1$ and $0<\delta<1$ are the reporting rates of state and combo governance, respectively. Then:

$$
g_{c}^{*}=\frac{1}{\delta}\left(g_{c}+\lambda g_{s}^{*}-\mu\right)
$$

and we will estimate:

$$
g_{c}=\delta \alpha+(\delta \beta+\lambda) g_{s}^{*}+\mu+\delta \epsilon
$$

We generally would have $\delta \beta \hat{+} \lambda<\beta$, except in a specific situation: when gang governance is high and the state is far away, but there is no misreporting when the government is close. 